\title{
Air Quality, Atmospheric Variables and Spread of COVID-19 in Delhi (India): An Analysis
}

\section{Aerosol and Air Quality Research}

Special Issue:

Special Issue on COVID-19 Aerosol Drivers, Impacts and Mitigation (XI)

\section{Abhishek Dutta, Wanida Jinsart*}

Department of Environmental Science, Faculty of Science, Chulalongkorn University Pathumwan, Bangkok 10330, Thailand

\section{ABSTRACT}

Based on a time series analysis of the criteria pollutants, meteorological parameters, and COVID-19 positive cases, this paper explores the impact of epidemic prevention and control actions on air quality for five different periods of COVID-19 outbreak in Delhi, India. The study found that under the epidemic control measure during 11 May-19 June 2020, the average concentrations of atmospheric air pollutants $\mathrm{PM}_{2.5}, \mathrm{PM}_{10}, \mathrm{NO}_{2}$, and $\mathrm{CO}$ were reduced to $42.15 \mu \mathrm{g} \mathrm{m}^{-3}, 128.68 \mu \mathrm{g} \mathrm{m}^{-3}$ $27.31 \mathrm{ppb}$, and $0.83 \mathrm{ppm}$ respectively, and were $73.85 \%, 46.48 \%, 63.43 \%$, and $50.18 \%$ lower than the pre-COVID-19 level of January 2020, respectively. The steep fall of $\mathrm{PM}_{2.5}, \mathrm{NO}_{2}$, and CO was due to a drastic reduction in vehicular emission, but $\mathrm{PM}_{10}$ did not fall below the National Ambient Air Quality Standard. Between January 2020 to 11 May-19 June 2020 period, the pollutants $\mathrm{O}_{3}$ and $\mathrm{SO}_{2}$ increased significantly by $217.33 \%$ and $57.58 \%$ respectively. The rise of $\mathrm{SO}_{2}$ in Delhi was due to long-distance transfer, power plant emissions, and biomass burning. The sharp increase of $\mathrm{O}_{3}$ happened due to accumulation in the atmosphere. During the peak COVID-19 phase ( 9 April-10 May 2020) Delhi had unprecedented improved AQI classes of II and III only. However, the pivotal pollutants in terms of their cumulative contribution to the AQI classes were $\mathrm{PM}_{10}$ and $\mathrm{O}_{3}$. Low $\mathrm{RH}$ and low-temperature situations exhibited positive correlations with the new COVID-19 infection cases in Delhi. Comparatively lower $\mathrm{NO}_{2}$ level in the air demonstrated a significant negative correlation with new COVID-19 cases while average $\mathrm{SO}_{2}$ concentration in the air, when increased to $24.05 \mathrm{ppb}$, showed a negative correlation with new COVID-19 cases in Delhi. This study indicated a possibility of $\mathrm{O}_{3}$ exhibiting a positive correlation with new COVID-19 cases under the condition of comparatively low temperature and low humidity.

Keywords: COVID-19, Delhi, Air pollutants, Air Quality Index, Meteorological variables

Received: July 19, 2020

Revised: October 15, 2020

Accepted: October 27, 2020

${ }^{*}$ Corresponding Author:

jwanida2013@gmail.com

\section{Publisher:}

Taiwan Association for Aerosol Research

ISSN: $1680-8584$ print

ISSN: 2071-1409 online

\section{Copyright: The Author(s)}

This is an open access article distributed under the terms of the Creative Commons Attribution License (CC BY 4.0), which permits unrestricted use, distribution, and reproduction in any medium, provided the original author and source are cited.

\section{INTRODUCTION}

The COVID-19 epidemic or Coronavirus epidemic is a current epidemic reeling the world that causes severe acute respiratory syndrome (SARS Cov-2). The first case of COVID-19 was seen in Wuhan, China, in December 2019. The World Health Organization (WHO) declared the outbreak as a public health emergency of international concern on 30 January 2020 and later only on 11 March 2020, WHO declared it an epidemic. A similar outbreak has occurred in the past that of Severe Acute Respiratory Syndrome Coronavirus (SARS-CoV) and of the Middle East Syndrome Coronavirus (MERS-CoV) which created fear all over the world and the subsequent global health threat due to zoonotic disease (Al-Tawfiq et al., 2014). The present COVID-19 virus could spread more rapidly from one person to another than the other two zoonotic diseases of the past. Countries of the world resorted to non-pharmaceutical interventions 'lockdown' to fight out the invisible enemy like COVID-19 with different timeframes in the absence of treatment or a vaccine. Table S1 shows that out of the 44 countries, 34 countries announced 'lockdown' during March 2020, including India.

In India, the first case of COVID-19 was reported on 30 January 2020. On 22 March 2020, India observed a voluntary public curfew for spreading mass awareness, and from 24 March 2020, 
India announced an initial phase of nationwide lockdown for 21 days. Subsequently, because of the increasing number of confirmed cases, the lockdown period was further extended in steps. Due to the lockdown effect, keeping the vast population of the country in mind, the mortality rate is considered still less in India if compared with some other countries like the USA, China, France, and Italy (Krishnakumar and Rana, 2020).

The rate of spread of diseases and mortality is showing a differential pattern in different countries and even different regions of the same country (Contini and Costabile, 2020). Exploratory research studies are encouraged in multiple disciplines to unearth variables that are potentially involved in the spread of COVID-19 and related mortality or morbidity. Many studies around the world are indicating a possible role in air pollution and meteorological variables for the differences in disease impact across different geographic locations (Conticini et al., 2020). Extensively affected countries like Italy felt the urgent need for understanding the relative weight of air pollution and other confounders in containing the spread of the pandemic (Italian Aerosol Society, 2020). Coccia (2020a) found in a more recent study, in the context of 55 Italian cities, that cities with frequent high levels of ozone or particulate matter had a higher rate of COVID-19 infection and mortality. The positive effect of PM pollution and negative effect of temperature and humidity were found to be two important dimensions of COVID-19 infection spread in Italy (Carteni et al., 2020; Coker et al., 2020; Lolli et al., 2020). In a three French city study, two pollutants (PM 10 and $\mathrm{PM}_{2.5}$ ) were found to be correlated with COVID-19 mortality (Magazzino et al., 2020). Studies from China also claimed to have found a relationship between COVID-19 spread, air pollution, and meteorological variables. Ma et al. (2020) found that there was a positive correlation between COVID-19 mortality of Wuhan city with diurnal temperature range (DTR). In a Seoul (Korea) based study it was observed that air pollutants like $\mathrm{CO}_{2}, \mathrm{CO}$, and $\mathrm{NO}_{2}$ were mainly got influenced by lockdown restrictions rather than the handiwork of meteorological conditions (Park et al., 2020). In USA where COVID-19 speedily spread, there was a substantial reduction of ambient $\mathrm{NO}_{2}$ in cities like Los Angeles, Fresno, Bakersfield, and San Francisco due to COVID-19 related containment measures (Naeger et al., 2020). Pansini and Fornacca (2020) in a three-country study of China, Italy, and USA, indicated a possible role of poor air quality, namely with $\mathrm{PM}_{2.5}$, $\mathrm{CO}$, and $\mathrm{NO}_{2}$ with COVID-19 inflicted mortality. He et al. (2020) studied the air quality indices (AQIs) in Chinese cities, both with and without lockdown, and found the much-improved air quality in the authority enforced lockdown cities in comparison. The role of climate variables on the daily new cases of COVID-19 related deaths was explored in the origin city of the pandemic i.e., Wuhan and found a significant correlation between AQI, humidity, and mortality (Fareed et al., 2020). Similarly, Zhang et al. (2020) threw light on the total effect of ambient temperature and air quality on COVID-19 transmission in China and indicated that rising temperature restricted deterioration of air quality which in turn reduced disease transmission. Bilal et al. (2020) echoed in a similar line and emphasized the strong connection found out between temperature and COVID-19 infection spread in Germany and credited the 'controlled' pollution status for restraining the pandemic spread in the country. With the upswing of the pandemic, the government imposed several restrictions on vehicle movements in worst effected Chinese cities to control air pollution, and the private vehicle restriction policy could bring down $\mathrm{PM}_{2.5}$ pollution by $32 \%$ (Chen et al., 2020). Li and Tartarini (2020) highlighted that $\mathrm{NO}_{2}$ and $\mathrm{SO}_{2}$ had the highest reduction in concentration during the lockdown period in Singapore and linked their associations with restricted mobility trends.

The success or failure of efforts to defeat COVID-19 depends on the air quality prevailing in the hugely populated Indian cities (Coccia, 2020b). Investigation of air quality and its relationship with COVID-19 cases is highly important where both epidemic and air pollutions are currently high (Zoran et al., 2020). The previous reports have also been showing air pollution (both ambient and household) as key risk factors in terms of disease spread for the Indian population (Cowling et al., 2014; Gargava and Rajagopalan, 2015; Dutta and Jinsart, 2020).

Against the above background, in this paper, we first made a review of the literature related to air pollution, and COVID-19 impact in the Indian cities contributed by various researchers in the recent past. The objective of the review was to explore the areas of prior scholarship, key findings of the research, air pollutants and meteorological considered, geographic (city) areas covered, and importantly finding research gaps to avoid duplication. We used the keywords such as air pollution, COVID-19, and Indian city to search for the relevant literature for the purpose at 
hand. We included the literature from computer searches and bibliographic databases (e.g., Google Scholar, Pub Med, Academia, and Research Gate) in the analysis. Approximately 110 articles published after the outbreak of COVID-19 in India in the English language on air quality related to Indian cities as well as COVID-19 found but 36 journal articles could be used for detailed review for the simple reason of their proximity with the objective in hand (Table 1). Out of 36 journal articles reviewed, 25 (70\%) studies considered the highly polluted Indian capital city Delhi, as their study location while others explored the lockdown effect of different state capitals and also small cities of India (Table S2). These studies successfully indicated the lockdown effect on different air pollutants by considering different time- periods (phases), both before and after the formal lockdown date, i.e., 25 March 2020. The current analysis presented as a part of this work differs from previous lockdown studies (Table 1) in the following unique ways. Firstly, five different phases of the epidemic outbreak were considered for time series analysis of the particulate matter, gaseous pollutants, meteorological parameters, new positive COVID-19 cases, and cumulative total COVID-19 cases in Delhi. This consideration of 1-5 phases of lockdown period and analyses of air pollutants thereof has allowed developing critical understanding in respect of air pollution for an extended period covering 1 January 2020 to 19 June 2020. Besides, how different levels of regulatory enforcement can affect air pollution concentrations of the most polluted city in the world became apparent. Secondly, in this study, the interaction of COVID-19 morbidity with environmental parameters (both criteria pollutants and meteorological variables) of Delhi has been explored through correlation and time-series analyses under two different periods of lockdown. The impact of environmental pollutants and climate indicators on the outbreak of COVID-19 has gained considerable attention in the recent literature, mostly in highly COVID-19 affected countries like China, Italy, and the USA. The exploration of the interaction of COVID-19 morbidity with environmental parameters and findings thereof is essential also for Indian policymakers to decide the future course of pandemic preventive action for the city of Delhi. Thirdly, unlike previous efforts (Table 1), this study has not only made a comparison of air pollutants prevailed during pre and post lockdown phases and established the AQI classes, but also made an in-depth analysis of indicatory air pollutants in each class of AQIs. The understanding of how the predominance of indicatory air pollutants altered during the different phases of lockdown measures is a valuable reference for future research on improving the air quality of Delhi.

The objective of this paper, therefore, is to fill the above-noted research gaps by investigating, comparing, and discussing the air quality of Delhi, including the air pollutants $\mathrm{PM}_{2.5}, \mathrm{PM}_{10}, \mathrm{SO}_{2}$, $\mathrm{NO}_{2}, \mathrm{CO}$, and $\mathrm{O}_{3}$, and AQIs from January to 19 June 2020 under five different phases of pre and post lockdown. Also, to specifically indicate the impact of the COVID-19 epidemic prevention and control actions on air quality with the identification of indicatory air pollutants for the different AQI classes. Additionally, to establish the interaction of COVID-19 morbidity with environmental parameters (both criteria pollutants and meteorological variables) of Delhi for the lockdown periods through correlation and time-series analyses and come out with some critical findings related to how air quality could play a supplementary role in controlling the current epidemic.

\section{METHODS}

The state-wise spread of COVID-19 cases in India has been assessed to single out Delhi as the state/city most affected in terms of the infection spread per million population. Day wise time series data for particulate matter, gaseous pollutants, meteorological parameters, new positive COVID-19 cases, and cumulative total COVID-19 cases were collected and analyzed for the five different time-periods (phases) of the epidemic outbreak in the city of Delhi. The air pollutants considered are a particulate matter of diameter less than 2.5 microns and 10 microns $\left(\mathrm{PM}_{2.5}\right.$ and $\left.\mathrm{PM}_{10}\right)$, Ozone $\left(\mathrm{O}_{3}\right)$, Nitrogen Dioxide $\left(\mathrm{NO}_{2}\right)$, Carbon Monoxide $(\mathrm{CO})$, and Sulphur Dioxide $\left(\mathrm{SO}_{2}\right)$ while the meteorological parameters are temperature, and relative humidity $(\mathrm{RH})$. The daily average data of these pollutants were collected from the Central Pollution Control Board (CPCB). The daily average data in respect of meteorological variables were collected from the Central Meteorological Department, Delhi.

The five phases considered were January 2020 (Phase 1), February 2020 (Phase 2), March 2020 


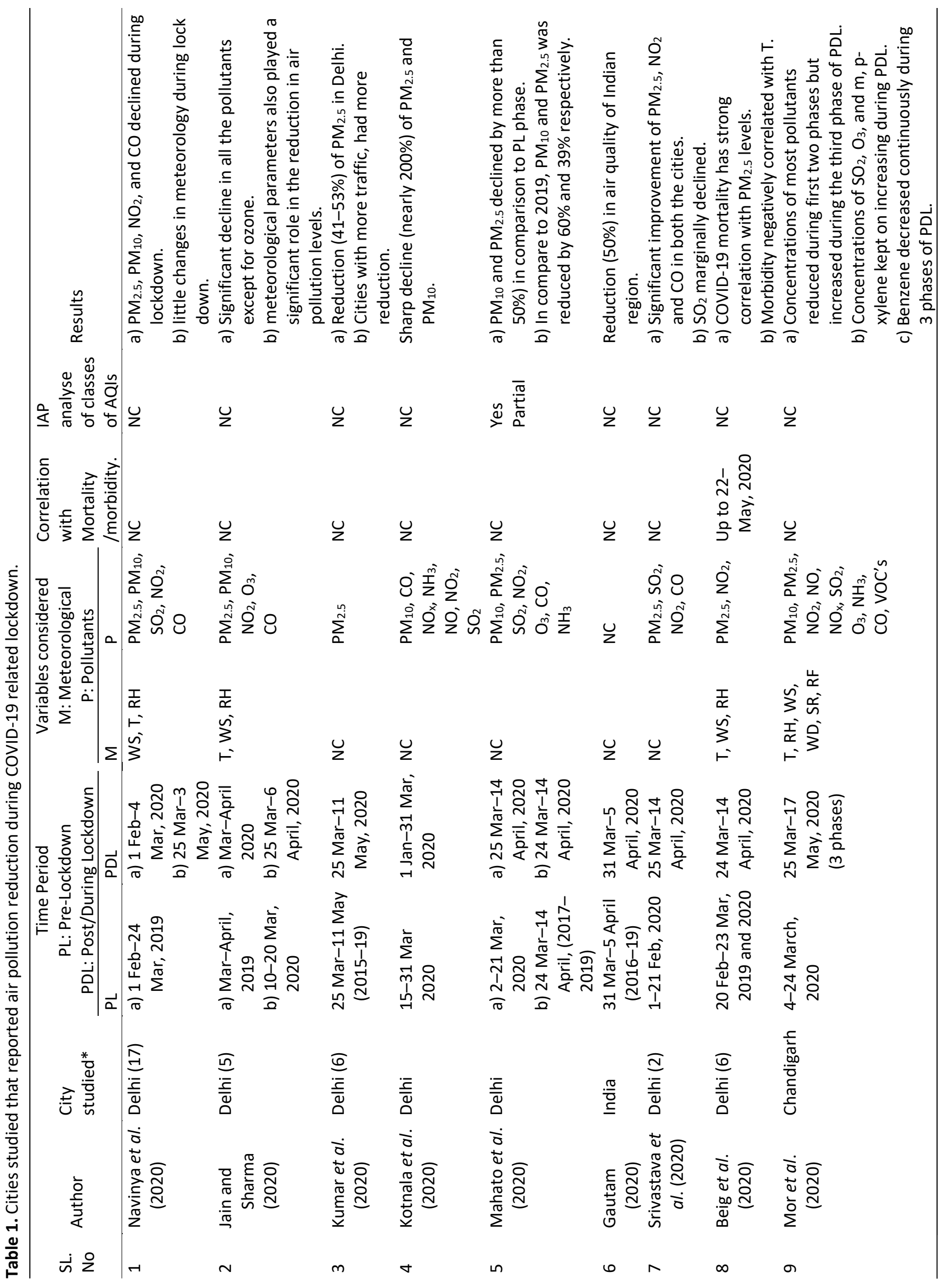




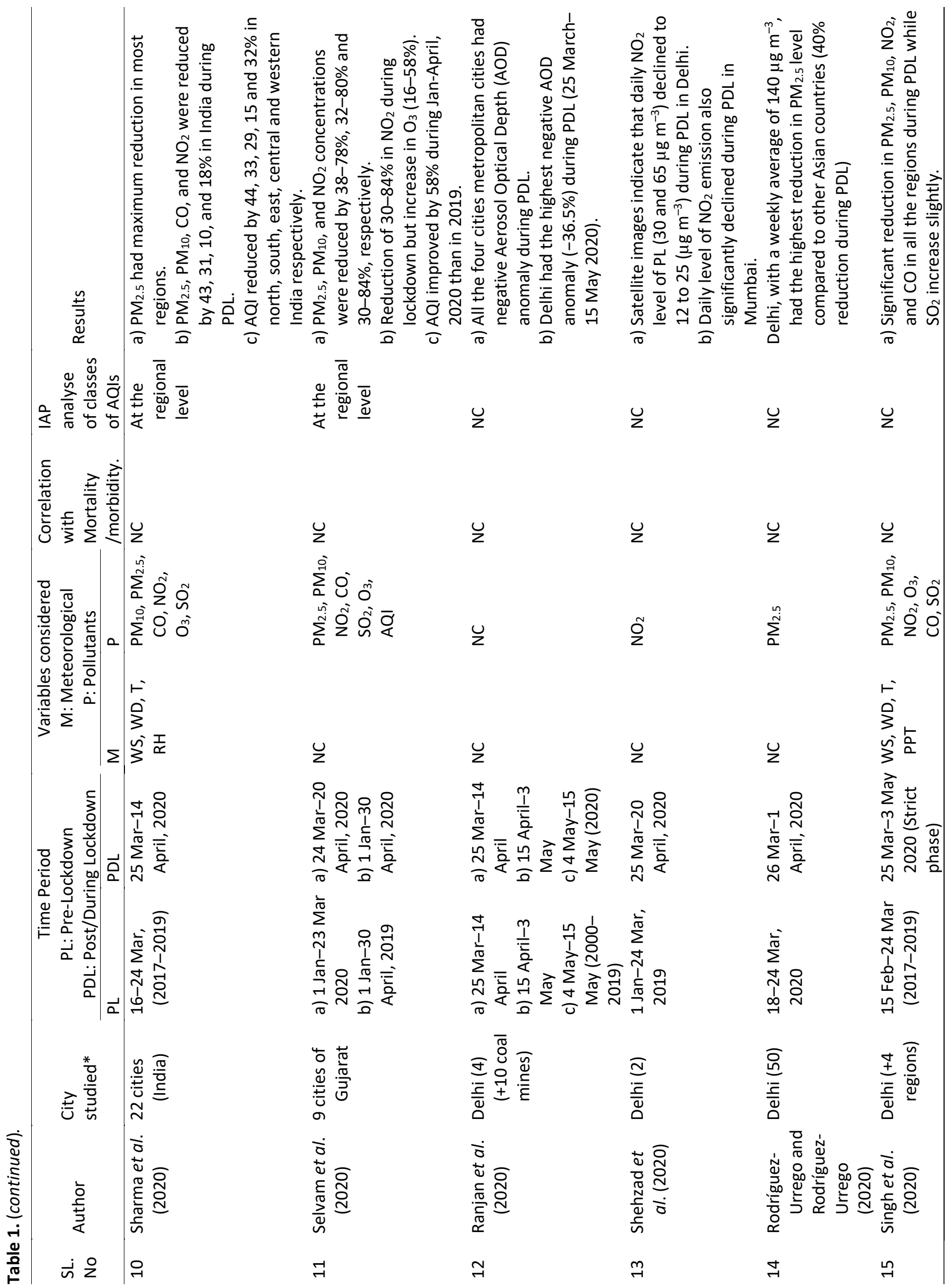




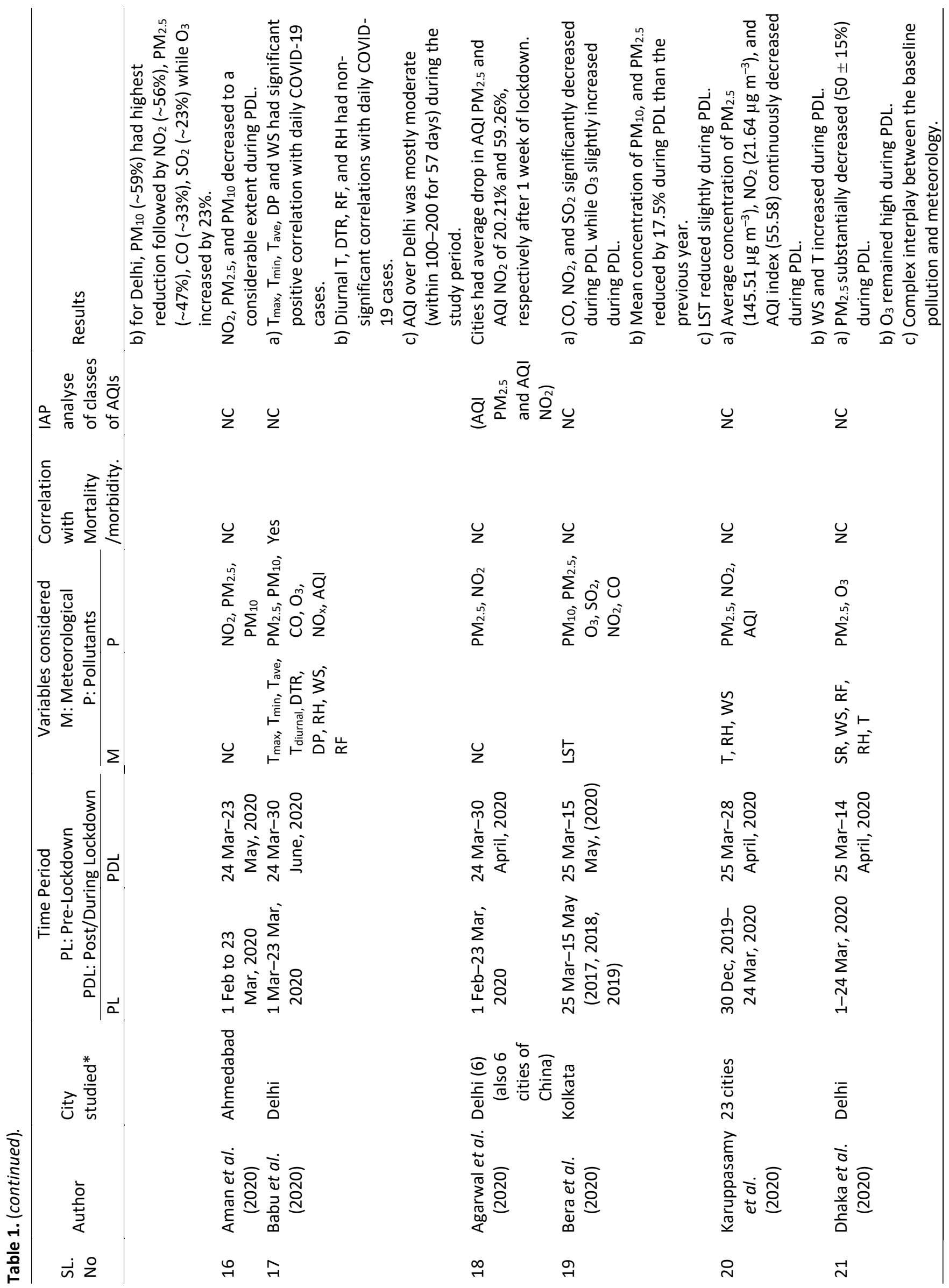




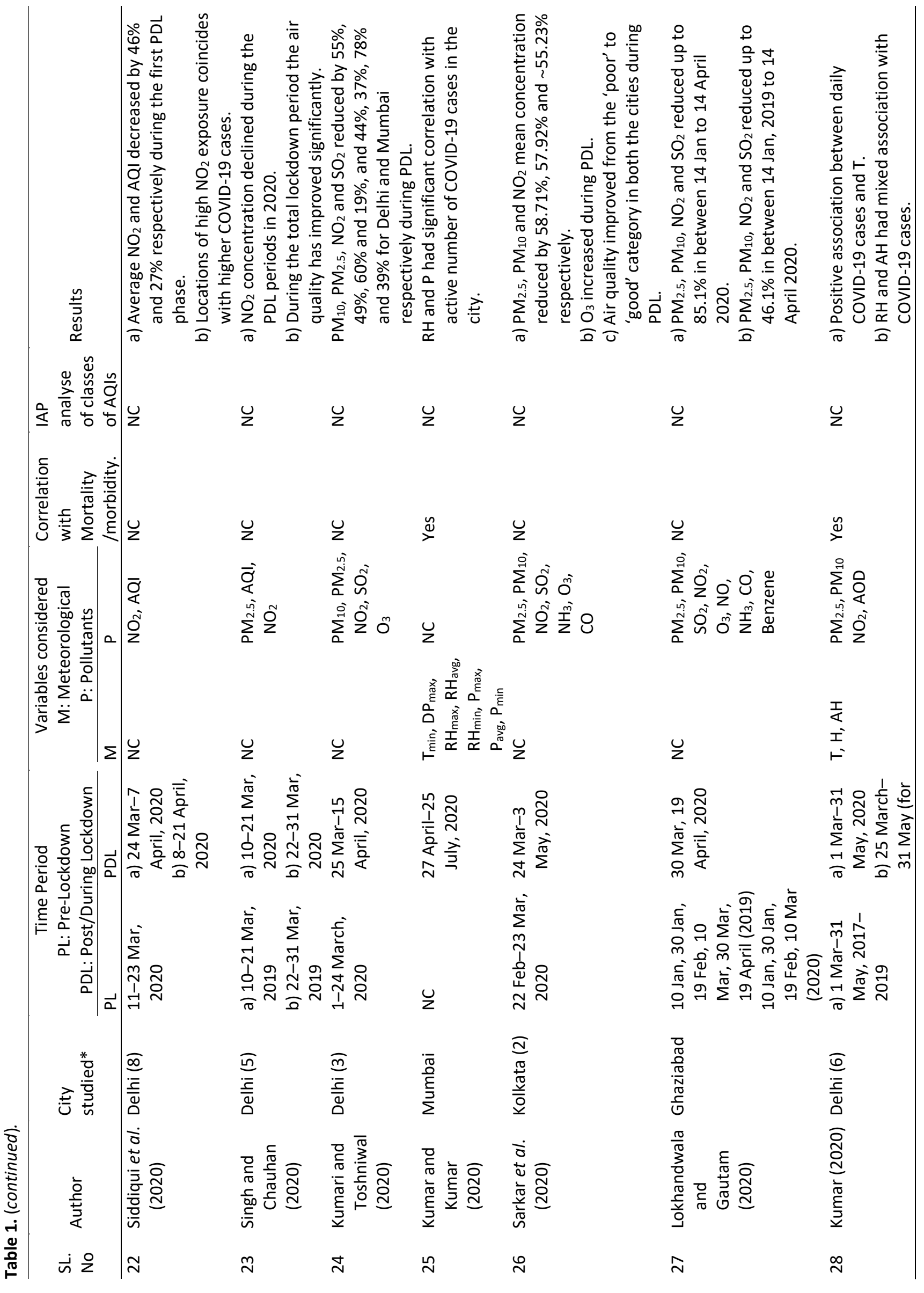




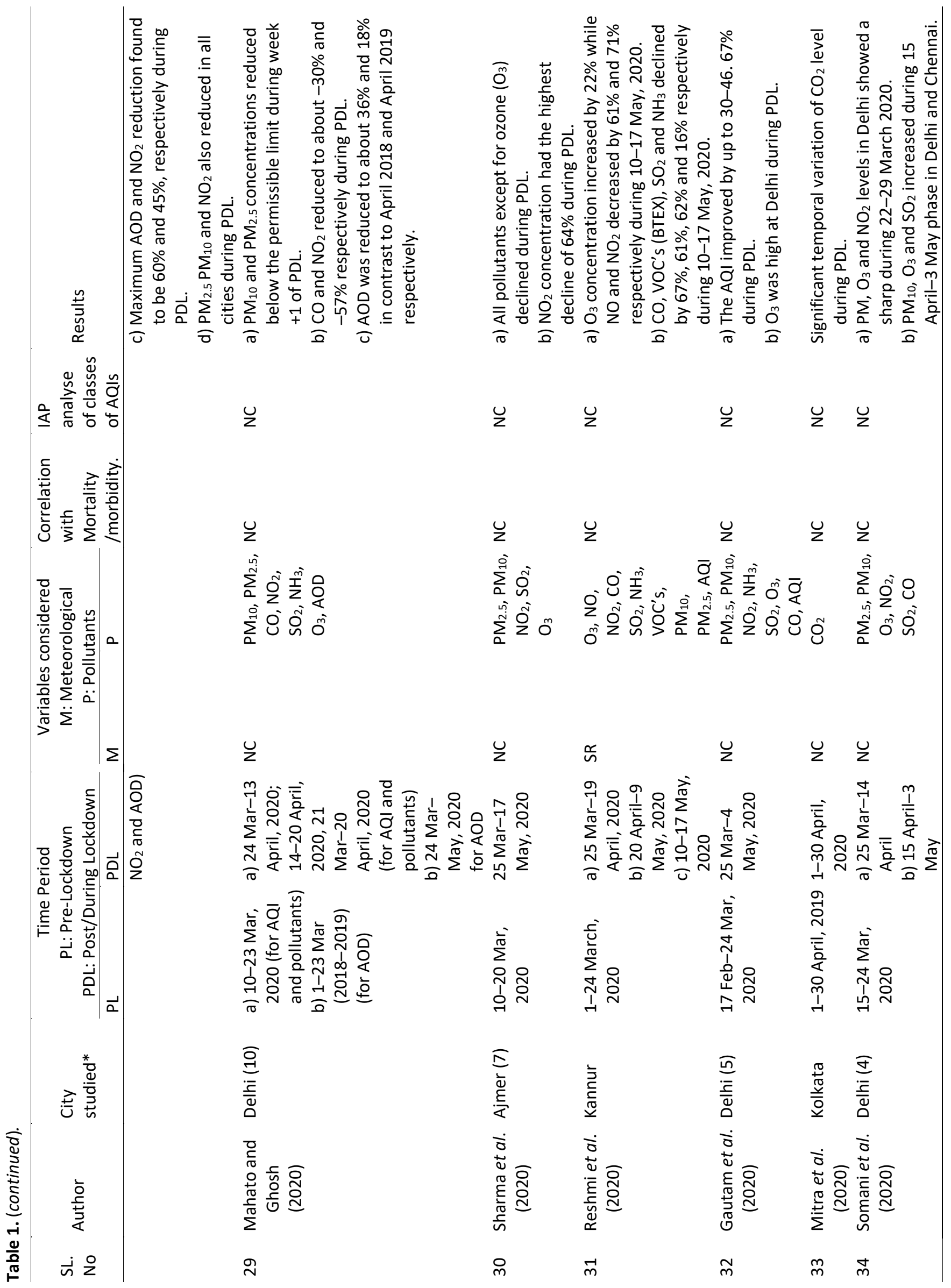




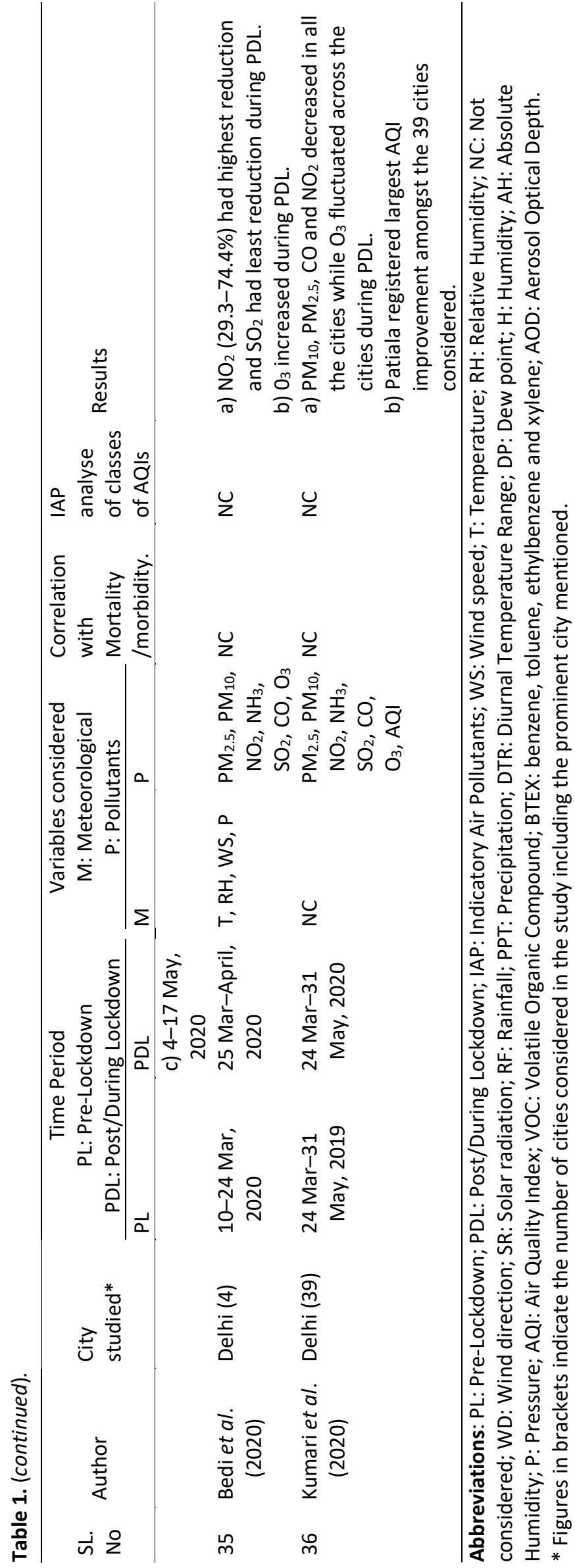


(Phase 3), 9 April-10 May 2020 (Phase 4), and 11 May-19 June 2020 (Phase 5). Phase 1 was a period when there were no cases of reported COVID-19 infection in the city with no real epidemic control measures in place. Phase 2 was characterized by no positive COVID-19 cases reported, but the city was readying epidemic control measures in case of an outbreak of the epidemic. During phase 3 , the city made a slow start of reporting COVID-19 positive cases with a rapid increase later in tandem with activated epidemic control measures like lockdown by the government. Phase 4 witnessed a rapid increase in new cases of COVID-19 infection with strict enforcement of epidemic control measures all around the city. During phase 5, there was a rapid increase in new cases of COVID-19 infection, but with the initiation of 'unlocking' operation or relaxation in the city. The daily 'major pollutant' was also identified to understand their presence and comparative contribution to the constitution of the Air Quality Index (AQI) for the city during the five phases of the COVID-19 outbreak.

Descriptive statistics and Pearson's correlation coefficients have been used to analyze the behavior of criteria pollutants and meteorological parameters with respect to the spread of infection (daily new COVID-19 cases) since the advent of the diseases in Delhi from March through 19 June 2020. The air pollutants considered are $\mathrm{PM}_{2.5}, \mathrm{O}_{3}, \mathrm{NO}_{2}$, and $\mathrm{SO}_{2}$ while the meteorological parameters are temperature and $\mathrm{RH}$. The analysis has been done for two different time periods, one; 1 March-10 May marked by inception and rapid increase of the diseases with strict enforcement of epidemic control measures, and two; from 11 May-19 June 2020 marked by the rapid increase of the diseases but with initiation of 'unlock' operation.

\section{STUDY LOCATION}

The study was conducted in Delhi, the capital of India (Fig. 1). Delhi is in the list of the top 20 most populated cities in the world. Burning of fuels, industrial factories, construction sites, power plants, stubble burning of agricultural biomass residue, and vehicular movement is found to be the primary cause of instantaneous air pollution in the city. Delhi has an extreme climate. It is very hot in summer (April-July) and cold in winter (December-January). The average temperature can vary from $25^{\circ} \mathrm{C}$ to $45^{\circ} \mathrm{C}$ during the summer and $22^{\circ} \mathrm{C}$ to $5^{\circ} \mathrm{C}$ during the winter. The spring season is February to March while the monsoon session is from July to Mid-September.

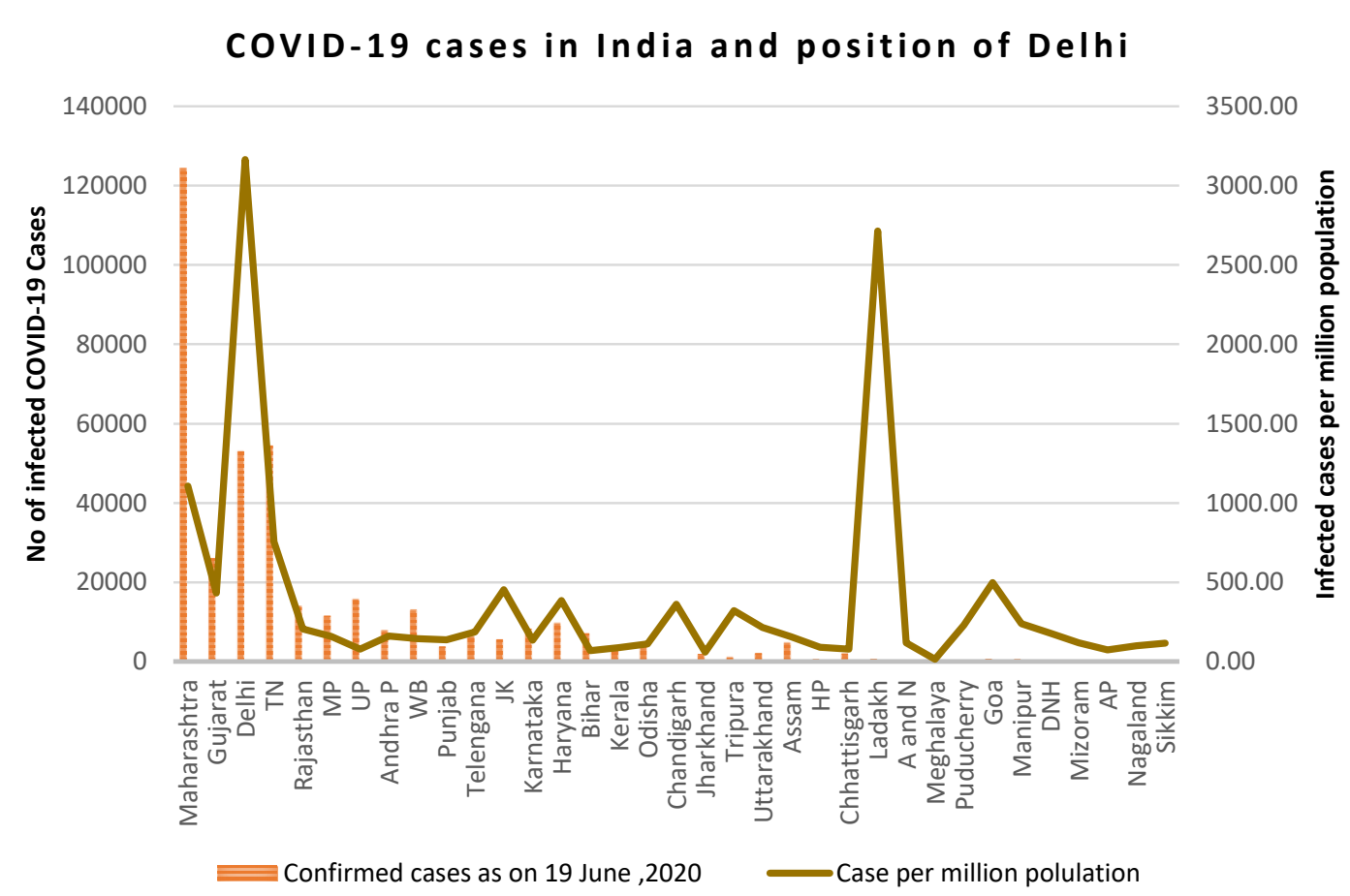

Fig. 1. State-wise COVID-19 cases and infected cases per million population. 


\subsection{The Onset of COVID-19 in Delhi}

In India, as of 19 June 2020, the total number of confirmed cases stood at 385,783 with statewise variations (COVID-19 Dashboard India, 2020). As can be seen from Table S3 and Fig. 1, the state of Maharashtra topped the list with 124,331 cases, and six states like Maharashtra, Gujarat, Delhi, Tamil Nadu (TN), Rajasthan, and Uttar Pradesh (UP) accounted for more than $74 \%$ of the total confirmed cases of India. In terms of cases of infection per million population, the capital city, Delhi is ahead of other Indian states with 3,164 cases per million population. The first COVID-19 positive case surfaced in Delhi on 4 March 2020 and thereafter rapidly increased in the subsequent months with 3,395 in April, 16,329 in May, and 33,272 during June (up to 19 June 2020) (Health \& Family Welfare, Delhi, 2020).

Table 2 and Fig. 2 below depicts the history of the spread of the highly infected diseases in the city of Delhi. The infection spread in Delhi fluctuated with the highest 3,137 cases per day to zero, the average being 477 cases per day, during 1 March-19 June 2020. The dispersion of COVID-19 cases around the mean stood at $142.76 \%$ as revealed from the co-efficient of variation. Up to 24 March, i.e., on the day Government of India formally declared 'lockdown' in the country there were only 31 cases in Delhi. Then came a 'super spreader' in the form of a Tablighi Jamaat, an Islamic religious gathering that took place at Nizamuddin, Delhi. The rise of cases became comparatively steeper after that in Delhi as evident from the fact that as of 30 April there were 3,515 COVID-19 cases in Delhi which rose to 6,929 by 10 May 2020 by registering a $97 \%$ rise. The spike in the number of confirmed cases in April and May 2020 can easily be noticed in Fig. 2.

\subsection{Air Pollution in Delhi: A Comparison}

The average concentrations for $\mathrm{PM}_{2.5}, \mathrm{PM}_{10}, \mathrm{SO}_{2}, \mathrm{CO}, \mathrm{NO}_{2}$, and $\mathrm{O}_{3}$ in all the five phases of COVID-19 infection spread in Delhi are shown and compared in Figs. 3(A)-3(F), respectively. The Fig. 3(A) indicates that during January 2020, the average $P_{2} M_{2.5}$ concentration was recorded as $161.17 \mu \mathrm{g} \mathrm{m}^{-3}$ in Delhi with a minimum of $65.95 \mu \mathrm{g} \mathrm{m}^{-3}$ and a maximum of $444.47 \mu \mathrm{g} \mathrm{m}^{-3}$. During February, Delhi recorded an average $\mathrm{PM}_{2.5}$ concentration of $114.67 \mu \mathrm{g} \mathrm{m}^{-3}$ where maximum and minimum were $198.69 \mu \mathrm{g} \mathrm{m}^{-3}$ and $52.34 \mu \mathrm{g} \mathrm{m}^{-3}$ respectively. During March 2020, the average $\mathrm{PM}_{2.5}$ concentration went down to a further low of $50.30 \mu \mathrm{g} \mathrm{m}^{-3}$ with a maximum of only $93.6 \mu \mathrm{g} \mathrm{m}^{-3}$ and a minimum of $15.23 \mu \mathrm{g} \mathrm{m}^{-3}$. Interestingly, there was further lowering of $\mathrm{PM}_{2.5}$ in Delhi during the

Table 2. Spread of COVID-19 in Delhi.

\begin{tabular}{|c|c|c|c|c|c|c|}
\hline City & $\begin{array}{l}\text { Total cases of infection } \\
(01-03-20 \text { to } 19-06-20)\end{array}$ & $\begin{array}{l}\text { Maximum number of } \\
\text { cases reported in a day }\end{array}$ & $\begin{array}{l}\text { Minimum no of cases } \\
\text { reported in a day }\end{array}$ & Mean & SD & $\begin{array}{l}\text { Co-efficient of } \\
\text { variation (\%) }\end{array}$ \\
\hline Delhi & 53,116 & 3,137 & 0 & 476.53 & 683.15 & 142.76 \\
\hline
\end{tabular}

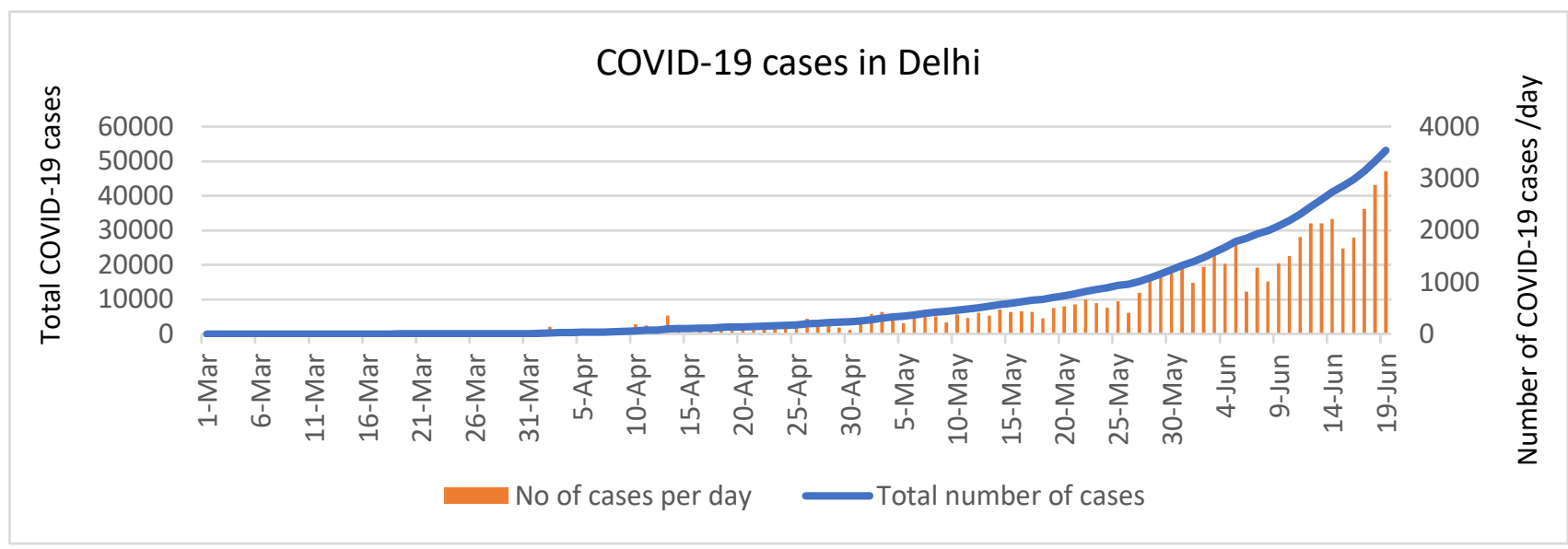

Fig. 2. Delhi and confirmed cases. 


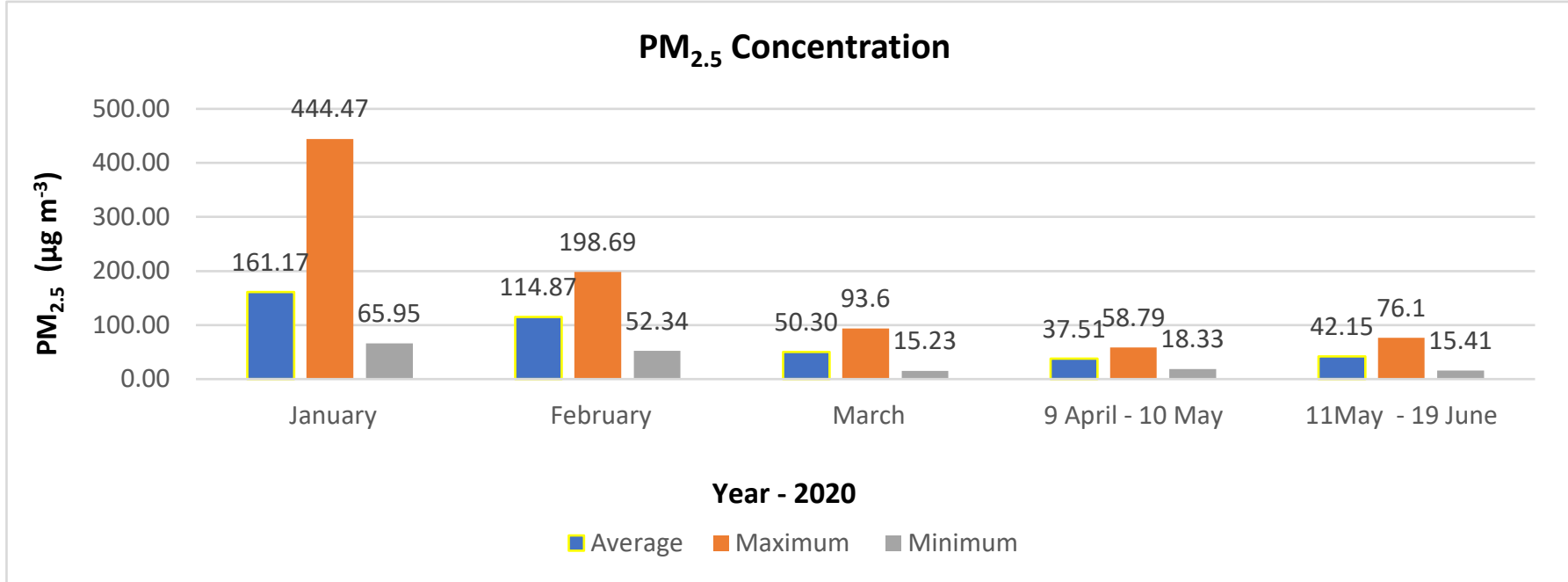

Fig. 3(A). The average PM2.5 concentrations of Delhi during five phases of COVID-19 outbreak.

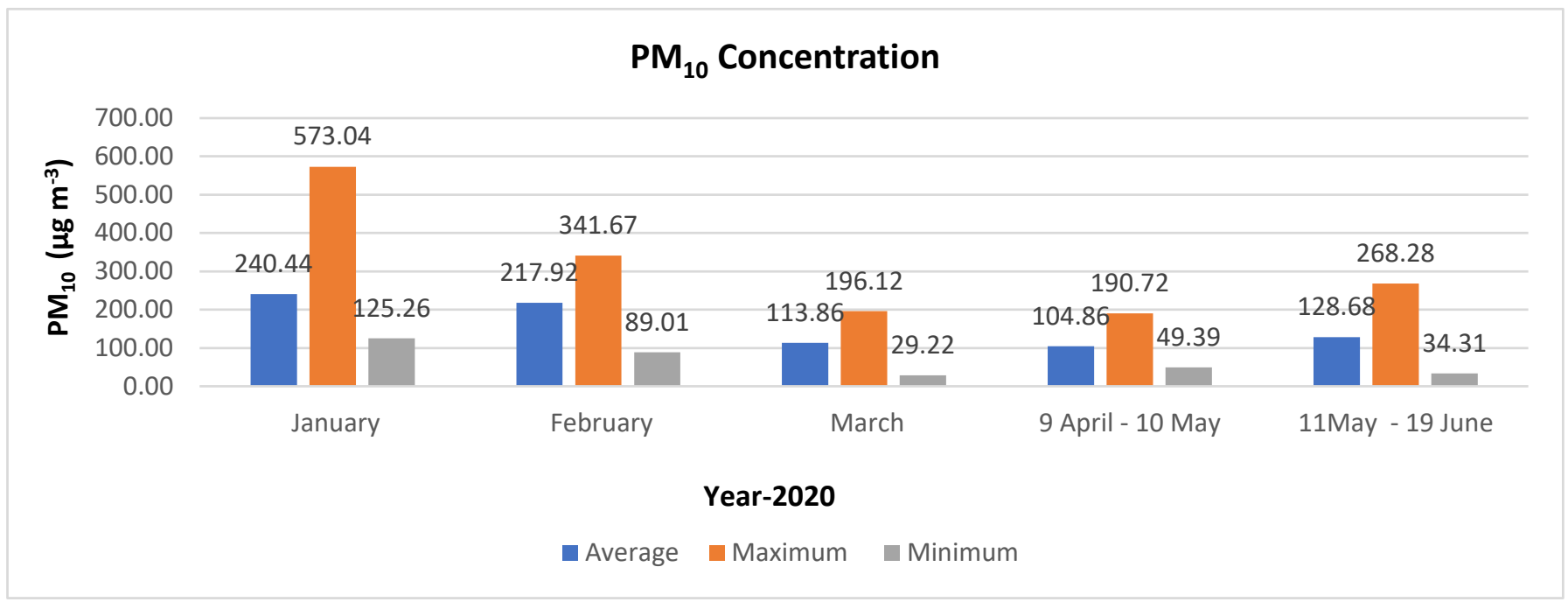

Fig. 3(B). The average $\mathrm{PM}_{10}$ concentrations of Delhi during five phases of COVID-19 outbreak.

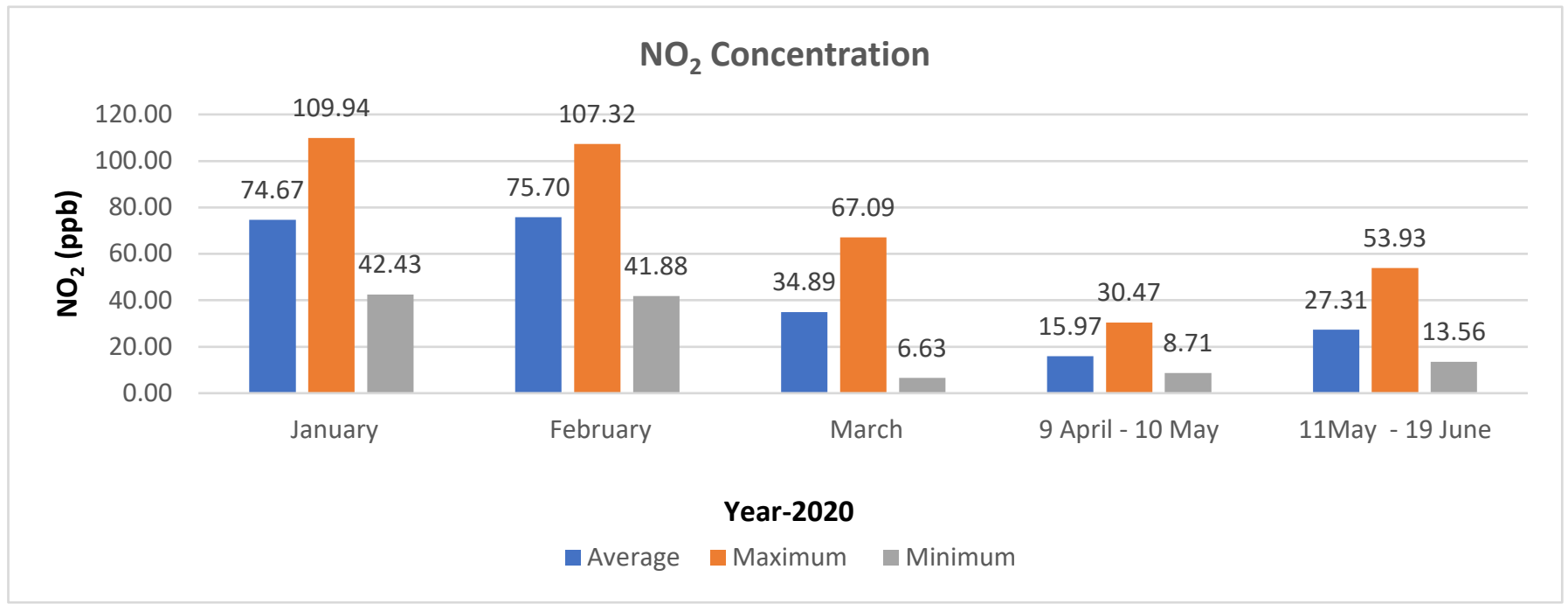

Fig. 3(C). The average $\mathrm{NO}_{2}$ concentrations of Delhi during five phases of COVID-19 outbreak. 


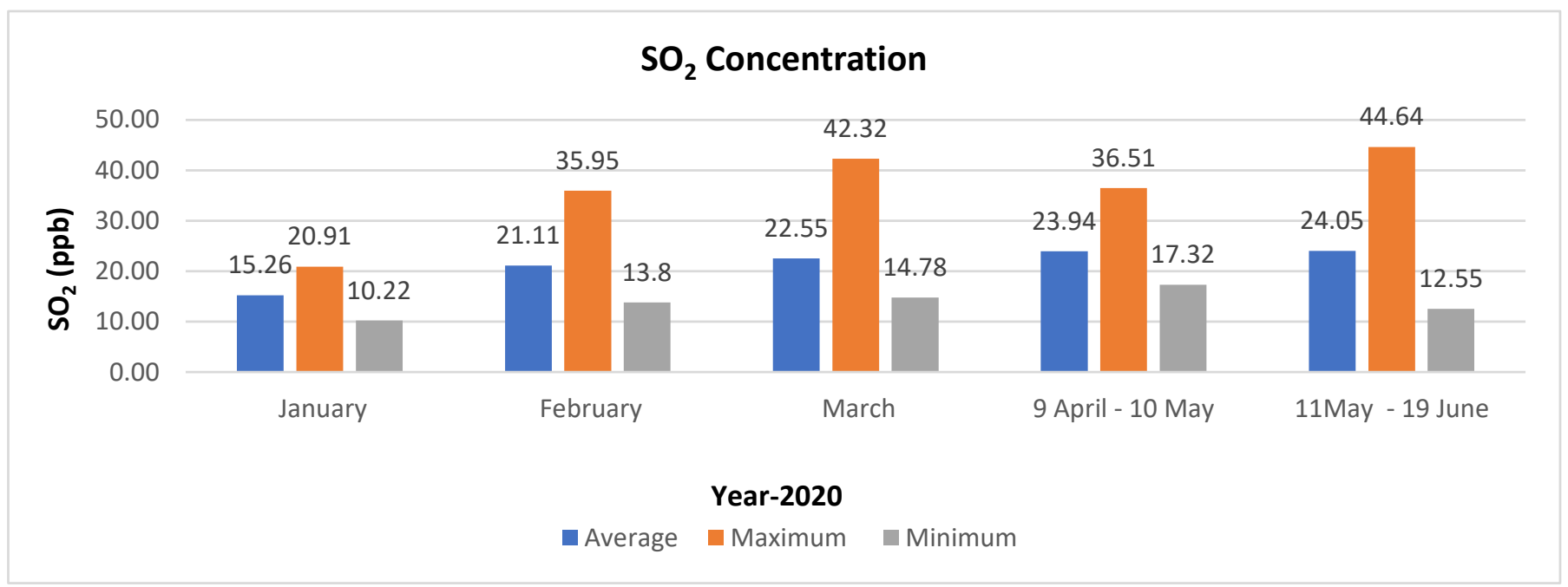

Fig. 3(D). The average $\mathrm{SO}_{2}$ concentrations of Delhi during five phases of COVID-19 outbreak.

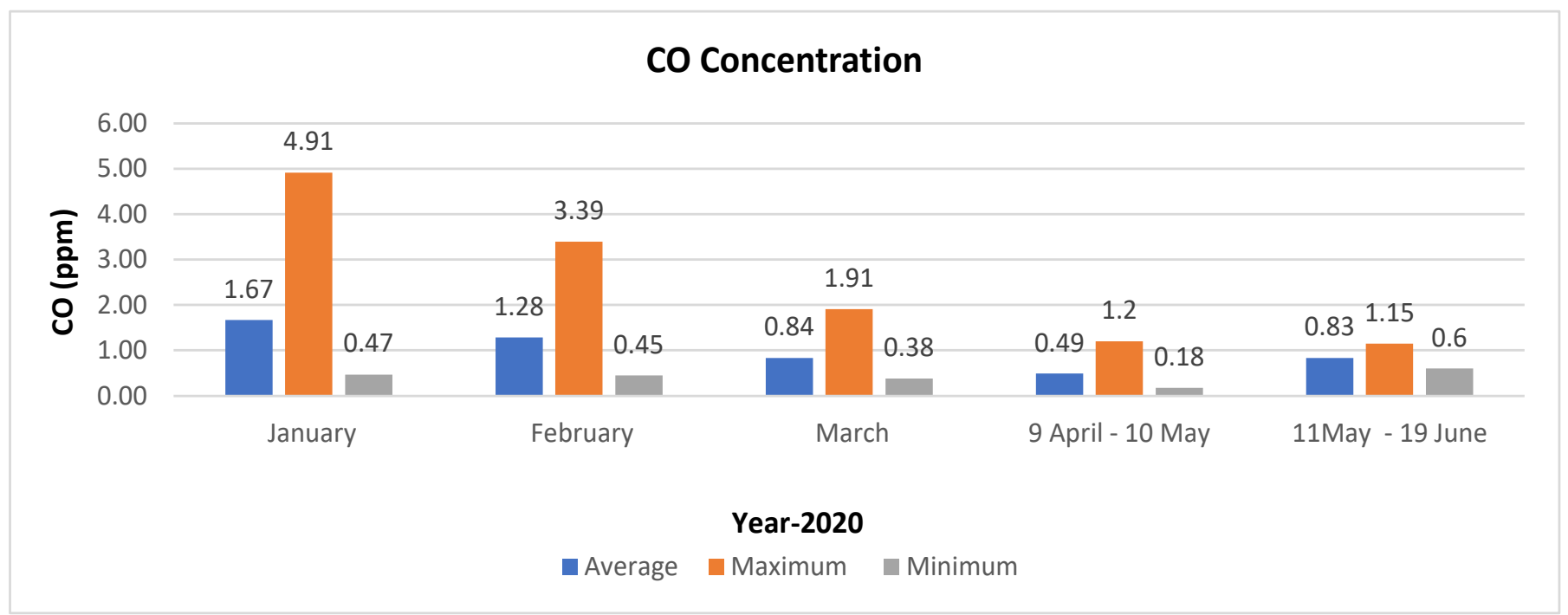

Fig. 3(E). The average CO concentrations of Delhi during five phases of COVID-19 outbreak.

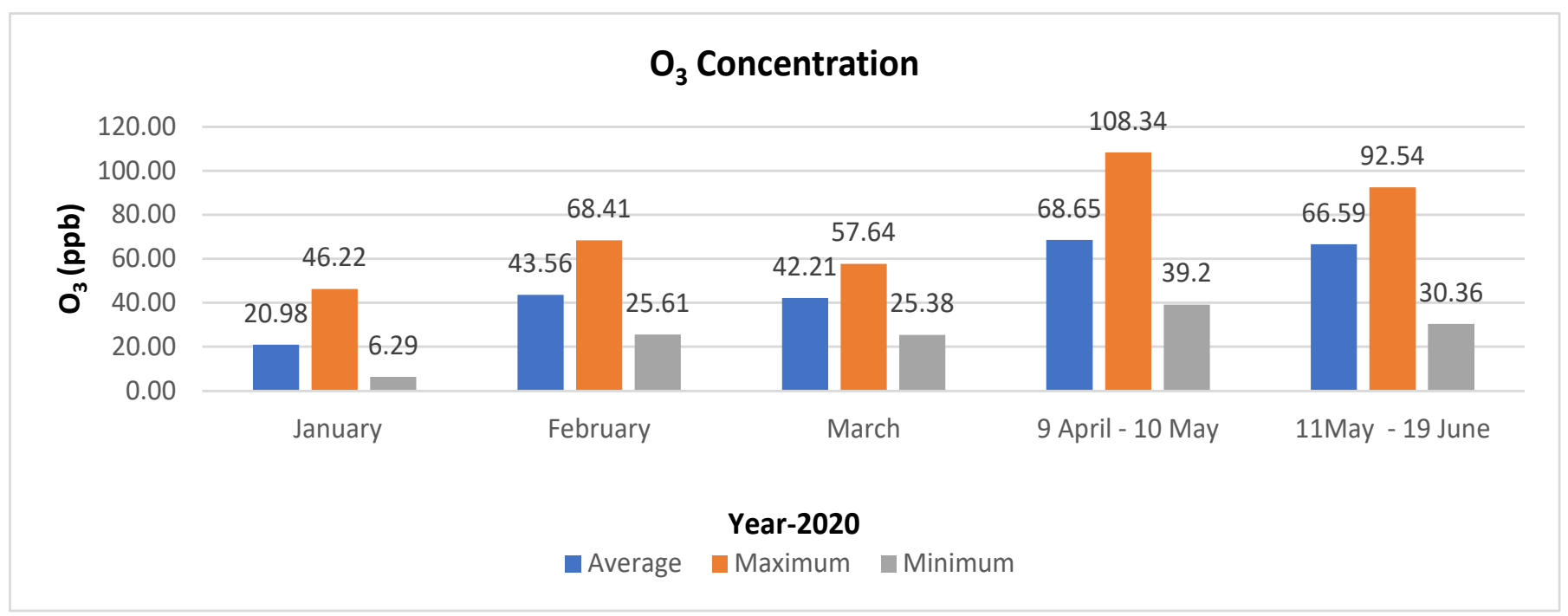

Fig. 3(F). The average $\mathrm{O}_{3}$ concentrations of Delhi during five phases of the COVID-19 outbreak. 
strict epidemic control period (9 April-10 May) with an average of only $37.51 \mu \mathrm{g} \mathrm{m}^{-3}$ where maximum and minimum were $58.79 \mu \mathrm{g} \mathrm{m}^{-3}$ and $18.33 \mu \mathrm{g} \mathrm{m}^{-3}$ respectively. With the initiation of 'unlock' operation, from 11 May-19 June 2020, the average $\mathrm{PM}_{2.5}$ concentration level somewhat increased to $42.15 \mu \mathrm{g} \mathrm{m}^{-3}$ with a maximum and minimum of $76.1 \mathrm{\mu g} \mathrm{m}^{-3}$ and $15.41 \mu \mathrm{g} \mathrm{m}^{-3}$ respectively. After the epidemic control measures in the form of lockdown enforced during March, the average $\mathrm{PM}_{2.5}$ concentration level decreased and came down within the National Ambient Air Quality Standard (NAAQS).

The Fig. 3(B) indicates that during January 2020, the average $\mathrm{PM}_{10}$ concentration was $240.44 \mu \mathrm{g} \mathrm{m}^{-3}$ in Delhi with a maximum as high as $573.04 \mu \mathrm{g} \mathrm{m}^{-3}$ and a minimum of $125.26 \mu \mathrm{g} \mathrm{m}^{-3}$. During February, Delhi recorded a maximum $\mathrm{PM}_{10}$ concentration of $341.67 \mu \mathrm{g} \mathrm{m}^{-3}$, a minimum of $89.01 \mathrm{~g} \mathrm{~m} \mathrm{~m}^{-3}$ with averages of $217.92 \mu \mathrm{g} \mathrm{m}^{-3}$. During March 2020, the $\mathrm{PM}_{10}$ concentration went further low of a maximum of $196.12 \mu \mathrm{g} \mathrm{m}^{-3}$ and a minimum of $29.22 \mu \mathrm{g} \mathrm{m}^{-3}$ with an average of $113.86 \mathrm{~g} \mathrm{~m} \mathrm{~m}^{-3}$. Interestingly, there was further lowering of $\mathrm{PM}_{10}$ in Delhi during the days of strict epidemic control measure (9 April-10 May) with a maximum of $190.72 \mu \mathrm{g} \mathrm{m}^{-3}$, a minimum of $49.39 \mu \mathrm{g} \mathrm{m}^{-3}$ while average stood at only $104.86 \mu \mathrm{g} \mathrm{m}^{-3}$. During the initiation of the 'unlocking' operation phase (11 May-19 June 2020), there was a slight increase in the average value of $\mathrm{PM}_{10}$ as $128.68 \mu \mathrm{g} \mathrm{m}^{-3}$ in the city. It may be noted here that even after the lockdown policy, the average $\mathrm{PM}_{10}$ concentration level remained higher than the NAAQS.

The Fig. 3(C) indicates that during January 2020, the average $\mathrm{NO}_{2}$ concentration was recorded as $74.67 \mathrm{ppb}$ with a maximum of $109.94 \mathrm{ppb}$ and a minimum of $42.43 \mathrm{ppb}$ in the city of Delhi. During February, Delhi recorded an average $\mathrm{NO}_{2}$ concentration of $75.7 \mathrm{ppb}$ with a maximum of $107.32 \mathrm{ppb}$ and a minimum of $41.88 \mathrm{ppb}$. During the onset of the COVID-19 epidemic (March 2020), the $\mathrm{NO}_{2}$ average concentration made a nosedive to $34.89 \mathrm{ppb}$ with a maximum of $67.09 \mathrm{ppb}$ and a minimum of $6.63 \mathrm{ppb}$. Interestingly, there was further lowering of $\mathrm{NO}_{2}$ in Delhi during the peak COVID-19 period ( 9 April-10 May) with maximum, minimum, and average of only $30.47 \mathrm{ppb}, 8.71 \mathrm{ppb}$, and $15.97 \mathrm{ppb}$ respectively. As the data reveals, in percentage term, the average $\mathrm{NO}_{2}$ concentration increased first between January to February marginally by $1.38 \%$ followed by a considerable reduction of $53.91 \%$ and $54.22 \%$ between February to March and March to 9 April-10 May period respectively. With the initiation of the unlocking operation, during 11 May-19 June, the $\mathrm{NO}_{2}$ concentration made a steady recovery with an average stood at $27.31 \mathrm{ppb}$.

It can be seen from Fig. 3(D) that during January 2020, the average $\mathrm{SO}_{2}$ concentration was recorded as $15.26 \mathrm{ppb}$ (maximum $20.91 \mathrm{ppb}$ and a minimum of $10.22 \mathrm{ppb}$ ) for the city of Delhi. During February, Delhi recorded a higher $\mathrm{SO}_{2}$ average concentration of $21.11 \mathrm{ppb}$ (maximum $35.95 \mathrm{ppb}$, minimum as $13.8 \mathrm{ppb}$ ). During March 2020, the average $\mathrm{SO}_{2}$ concentration jumped up further with $22.55 \mathrm{ppb}$ (maximum $42.42 \mathrm{ppb}$ and a minimum of $14.78 \mathrm{ppb}$ ). Interestingly, though there was a marginal decrease of the maximum level of $\mathrm{SO}_{2}$ in Delhi to $36.51 \mathrm{ppb}$ during the peak COVID-19 period ( 9 April-10 May) in comparison to March 2020 value, both minimum and average level had risen to $17.32 \mathrm{ppb}$ and $23.94 \mathrm{ppb}$ respectively. In percentage terms, the average $\mathrm{SO}_{2}$ concentration increased substantially by $38.29 \%$ first between January to February followed by a marginal increase of $6.85 \%$ and $6.16 \%$ between February to March and March to 9 April-10 May period respectively. From 11 May-19 June, the average value of $\mathrm{SO}_{2}$ was 24.05 which was only $0.5 \%$ higher than that of 9 April-10 May value.

Fig. 3(E) reveals that during January 2020, the maximum CO concentration was recorded as $4.91 \mathrm{ppm}$ and a minimum of $0.47 \mathrm{ppm}$, with an average of $1.67 \mathrm{ppm}$ for the city of Delhi. During February, Delhi recorded a maximum CO concentration of $3.39 \mathrm{ppm}$, a minimum of $0.45 \mathrm{ppm}$ with an average of $1.28 \mathrm{ppm}$. During March 2020, the maximum CO concentration was recorded as $1.91 \mathrm{ppm}$ and a minimum of $0.38 \mathrm{ppm}$ with an average of $0.84 \mathrm{ppm}$. Interestingly, the maximum, minimum, and average $\mathrm{CO}$ concentration further decreased to $1.2 \mathrm{ppm}, 0.18 \mathrm{ppm}$, and $0.49 \mathrm{ppm}$ respectively during the 9 April-10 May period. In percentage terms, the average CO concentration decreased by $23 \%$ first between January to February and followed by a decrease of $34.86 \%$ and 41.6\% between February to March and March to 9 April-10 May period respectively. However, with the initiation of unlocking operation, the average concentration of $\mathrm{CO}$ made a marginal recovery with an average 0.83 ppm during the 11 May-19 June period.

January 2020 recorded the maximum $\mathrm{O}_{3}$ concentration of $46.22 \mathrm{ppb}$ and a minimum of $6.29 \mathrm{ppb}$ with an average of $20.98 \mathrm{ppb}$ in Delhi which indicates substantial air presence of ground-level $\mathrm{O}_{3}$ 
in the pre-COVID-19 period as shown in Fig. 3(F). During February, Delhi recorded a further rise with maximum $\mathrm{O}_{3}$ concentration to $68.41 \mathrm{ppb}$ with a minimum of $25.61 \mathrm{ppb}$ and averages of $43.56 \mathrm{ppb}$. Interestingly, during March 2020, the maximum, minimum, and average $\mathrm{O}_{3}$ concentration was reduced to $57.64 \mathrm{ppb}, 25.38 \mathrm{ppb}$, and $42.21 \mathrm{ppb}$ respectively. However, again during the peak COVID-19 period (9 April-10 May), there was a substantial increase in the maximum, minimum, and average level of $\mathrm{O}_{3}$ in Delhi. In percentage term, the average $\mathrm{O}_{3}$ concentration was increased by about $63.64 \%$ in between January to February 2020 while in between March and 9 April-10 May period, the rise was of 107.63\%. However, during the 11 May-19 June period, there was a marginal decrease of $3 \%$ in the average $\mathrm{O}_{3}$ concentration level than that of the 9 April-10 May period.

\subsection{Effect of COVID-19 on PM and Gaseous Elements: Possible Reasons}

The average concentrations of criteria pollutants varied during all the five phases considered in the study. In percentage term, the reductions of the average concentration of $\mathrm{PM}_{2.5}$ in-between phase 1 to phase 2, phase 2 to phase 3 , phase 3 to phase 4 , and overall phase 1 to phase 5 were $28.73 \%, 56.21 \%, 25.42 \%$, and $73.85 \%$ respectively as shown in Table 3 below. The downturn of $\mathrm{PM}_{2.5}$ level in the capital city during phase 1 to phase 2 was due to the reinforcement of odd-even traffic rule from November 2019 onwards and closure of office and factories during mid of January 2020 due to festivals like Makar Sankranti and Pongal (Singh et al., 2011). The PM2.5 level also abruptly came down during phase 3 and phase 4 due to a complete lockdown enforced by the central government from the morning of 23 March 2020 onwards to prevent the spread of the COVID-19 epidemic. A marginal increase of $\mathrm{PM}_{2.5}$ level by $12.23 \%$ during phase 4 was due to the relaxation of lockdown initiated in the city. In totality, this study reveals an unprecedented $73.85 \%$ reduction of $\mathrm{PM}_{2.5}$ in the sixth most polluted city of the world during phase 1 to phase 5. The primary identified sources of $\mathrm{PM}_{2.5}$ in Delhi were secondary aerosols (23.2\%), soil dust (22.5\%), vehicle emissions (18.5\%), fossil fuel burning (13.1\%), biomass burning $(12.3 \%)$, industrial emissions (6.3\%) and sea salts (4.1\%) (Sharma and Mandal, 2017). Therefore, the steep reduction in $\mathrm{PM}_{2.5}$ may be due to the substantial reduction of vehicle emissions, soil dust, and industrial emissions because of the complete lockdown enforced during the epidemic outbreak. Table 3 further reveals that, in percentage terms, the reductions of the average concentration of $\mathrm{PM}_{10}$ during phase 1 to phase 5 was about 46.48\%. Possible reasons for the reduction of $\mathrm{PM}_{10}$ almost to half were the complete shutdown of construction activities and industrial production activities in the entire national capital region of Delhi due to the epidemic prevention and control actions.

From phase 1 to phase 2, the average $\mathrm{NO}_{2}$ concentration increased marginally by $1.38 \%$ showing that the industrial production and traffic activities did take time to get reduced as the importance of economic activities was put in the forefront and fear of COVID-19 related epidemic was yet to get into the people. However, once the government machinery was in action to invoke lockdown, the fall in the average level of $\mathrm{NO}_{2}$ concentration was the sharpest. From phase 2 to

Table 3. Increase/decrease in the average concentration level in Delhi.

\begin{tabular}{|c|c|c|c|c|c|c|c|}
\hline \multirow{2}{*}{ Time periods* } & \multicolumn{7}{|c|}{ Average concentration level: Increase/decrease } \\
\hline & $\mathrm{PM}_{2.5}\left(\mu \mathrm{g} \mathrm{m}^{-3}\right)$ & $\mathrm{PM}_{10}\left(\mu \mathrm{g} \mathrm{m}^{-3}\right)$ & $\mathrm{NO}_{2}(\mathrm{ppb})$ & $\mathrm{SO}_{2}(\mathrm{ppb})$ & $\mathrm{CO}(\mathrm{ppm})$ & $\mathrm{O}_{3}(\mathrm{ppb})$ & \\
\hline Phase 1 & 161.17 & 240.44 & 74.67 & 15.26 & 1.67 & 20.98 & \\
\hline Phase 2 & 114.87 & 217.92 & 75.70 & 21.11 & 1.28 & 43.56 & \\
\hline Phase 3 & 50.30 & 113.86 & 34.89 & 22.55 & 0.84 & 42.21 & \\
\hline Phase 4 & 37.51 & 104.86 & 15.97 & 23.94 & 0.49 & 68.65 & \\
\hline Phase 5 & 42.15 & 128.68 & 27.31 & 24.05 & 0.83 & 66.59 & \\
\hline Phase 1 to Phase 2 & $28.73 \%$ & $9.37 \%$ & $-1.38 \%$ & $38.29 \%$ & $22.99 \%$ & $107.57 \%$ & $\boldsymbol{1}$ \\
\hline Phase 2 to Phase 3 & $56.21 \%$ & $47.75 \%$ & $53.91 \%$ & $6.85 \%$ & $34.86 \%$ & $3.09 \%$ & $\Uparrow$ \\
\hline Phase 3 to Phase 4 & $25.42 \%$ & $7.91 \%$ & $54.22 \%$ & $6.16 \%$ & $41.60 \%$ & $62.62 \%$ & $\Uparrow$ \\
\hline Phase 4 to Phase 5 & 12.23 & 22.71 & $70.97 \%$ & $0.46 \%$ & $70 \%$ & $3 \%$ & $\downarrow$ \\
\hline Phase 1 to Phase 5 & 73.85 & 46.48 & 63.43 & 57.58 & 50.18 & 217.33 & $\Uparrow$ \\
\hline
\end{tabular}

* Phase 1 (January, 2020), Phase 2 (February, 2020), Phase 3 (March 2020), Phase 4 (9 April-10 May, 2020), Phase 5 (11 May19 June, 2020). 
phase 3 and phase 3 to phase 4, the average $\mathrm{NO}_{2}$ level fell by $53.91 \%$ and $54.22 \%$ respectively. While the origin of $\mathrm{SO}_{2}$ predominantly from natural sources worldwide, but in urban and industrial areas like Delhi, the manmade sources also prevail. The previous studies have shown that during the winter months (December-January), $\mathrm{SO}_{2}$ gets into the Delhi atmosphere through longdistance transfer from western Asia, northwestern Pakistan, Rajasthan, and Punjab provinces. Besides, coal-based thermal power plants at Panipat (in the northwestern side of Delhi) and Faridabad (in the southeastern side of Delhi), local industries, soil erosion, and biomass burning also contributes to the accumulation of $\mathrm{SO}_{2}$ in Delhi air (Goyal and Sidhartha, 2002; Datta et al., 2010). As shown in Table 3, the rise of $\mathrm{SO}_{2}$ concentration level during phase 1 to phase 5 by $57.58 \%$ was possibly due to a combination of long-distance transfer, power plant emissions in the vicinity, and biomass burning. Though local industries were closed, agriculture activities were allowed to continue in the periphery of Delhi to a great extent during the lockdown period also. Delhi usually experiences high CO concentration in the atmosphere because of sources like longdistance transfer over the Bay of Bengal from the Indo-Gangetic plains as well as local sources like the burning of firewood and emissions from the transport sector. This study records that from phase 3 to phase 4; there was about a 40.6\% drop in the CO average concentration in Delhi. It indicates that neither the local sources could be active nor the long-distance transfer of CO was possible because of pan India lockdown which affected the running of motor vehicles to a great extent (Tyagi et al., 2016).

Table 3 also reveals that the average concentration of $\mathrm{O}_{3}$ had a massive increase of $217.33 \%$ during the period of phase 1 to phase 5 , which was significantly high and alarming for a city like Delhi. The rise in $\mathrm{O}_{3}$ was a concern for Delhi during the non-COVID-19 time also and the authority, i.e., CPCB even initiated action to control the health effect caused by this dominant pollutant. Ozone is a reactive form of oxygen that is not directly emitted from any sources but formed with a reaction between nitrogen oxides (composed of nitrogen and oxygen) and hydrocarbons in the presence of sunlight. There may be two possible reasons for the significant rise of $\mathrm{O}_{3}$ during the outbreak of COVID-19 in Delhi. First, vehicular and industrial fumes gave rise to $\mathrm{NO}_{\mathrm{x}}$, and a higher level of $\mathrm{NO}_{x}$ contributed towards the forming of $\mathrm{NO}_{2} . \mathrm{NO}_{2}$ then dissociated to form $\mathrm{NO}$, and $\mathrm{O}$ in the presence of sunlight. Further, $\mathrm{O}$ combined with atmospheric $\mathrm{O}_{2}$ to form $\mathrm{O}_{3}$ in the atmosphere. Hence, under this process, the levels of $\mathrm{O}_{3}$ and $\mathrm{NO}_{2}$ are inextricably linked (Han et al., 2011). Second, when urban VOC emissions from a complex mix of sources like traffic, industry, solvents, and waste burning were not possible due to the lockdown effect, a new inverse relationship between $\mathrm{O}_{3}$ concentration and $\mathrm{NO}_{2}$ concentration emerged. The second possible reason seems to be relevant for high ground-level $\mathrm{O}_{3}$ in Delhi air where lower $\mathrm{NO}_{2}$ rather contributed more $\mathrm{O}_{3}$ to accumulate in the atmosphere as not enough $\mathrm{NO}$ was there in the air to react with $\mathrm{O}_{3}$ to form $\mathrm{O}_{2}$ (Chameides et al., 1992; Biswas et al., 2019).

\subsection{AQI Distribution}

India has its own national air quality indices (AQIs), corresponding to different national air quality standards. The AQI was launched by the Indian government to make India pollution-free. The AQI for a given pollutant concentration (Cs) is based on a linear segmented principle (Nigam et al., 2015). The AQI Eqs. (1) and (2), as shown below, are based on dose-response relationships of pollutants to obtain breakpoint concentration which is considered to be most robust for decision making (CPCB, 2014).

$I_{P}=\left[\left\{\frac{I_{H I}-I_{L O}}{B_{H I}-B_{L O}}\right\} \times\left(C_{P}-B_{L O}\right)\right]+I_{L O}$

$\mathrm{AQI}=\operatorname{Max}\left(I_{P}\right)$ (where $\mathrm{p}=1,2,3, \ldots, \mathrm{n}$; denotes $\mathrm{n}$ pollutants $)$

where,

Ip - Air quality sub-index for air pollutant $p$;

$B_{\mathrm{HI}}$ - Breakpoint concentration greater or equal to given Concentration;

$\mathrm{B} \mathrm{LO}_{\mathrm{O}}$-Breakpoint concentration smaller or equal to given Concentration;

$C_{p}$ - Concentration of pollutant $p$; 
$\mathrm{I}_{\mathrm{HI}}-\mathrm{AQI}$ value corresponding to $\mathrm{B}_{\mathrm{HI}}$;

ILO - AQI value corresponds to B⿺辶.

India had six AQI categories, namely Good, Satisfactory, Moderately polluted, Poor, Very Poor, and Severe. The different ranges of each category are as shown in Table 4 below along with the color codes for each category.

The outbreak of COVID-19 had its impact on the AQI values of Delhi too. The AQIs of Delhi during the five phases considered in this study were calculated out and shown in Figs. $4(A)-4(E)$, respectively. As shown in Fig. 4(A), during January 2020, the AQIs in Delhi ranged from a minimum of 120 to a maximum of 579, with an average of 310.03 and a standard deviation of 94.93 . Fig. 4(B), indicates that the AQI values fell substantially during February and ranged between a minimum of 89 to a maximum of 361 with an average value of 250.57 and a standard deviation of 82.02 . The minimum, maximum, and average values of February AQIs were $37.67 \% .25 .83 \%$, 19.3\% lower than the corresponding values recorded during January 2020.

The AQI values of Delhi further tumbled down during March to a new low as shown in Fig. 4(C). During March, the maximum AQI was 212 with a minimum of 29 and an average 109.58 with a

Table 4. National Air Quality standard of India.

\begin{tabular}{lll}
\hline Class & AQI Range & Air Quality effects on health \\
\hline Class I & Good (0-50) & Minimal Impact \\
Class II & Satisfactory (51-100) & Minor breathing discomfort to sensitive people \\
Class III & Moderate (101-200) & Breathing discomfort to people with lung, heart disease, children, and older adults \\
Class IV & Poor (201-300) & Breathing discomfort to people on prolonged exposure \\
Class V & Very Poor (301-400) & Respiratory illness to the people on prolonged exposure \\
Class VI & Severe $(>401)$ & Respiratory effects even on healthy people \\
\hline
\end{tabular}

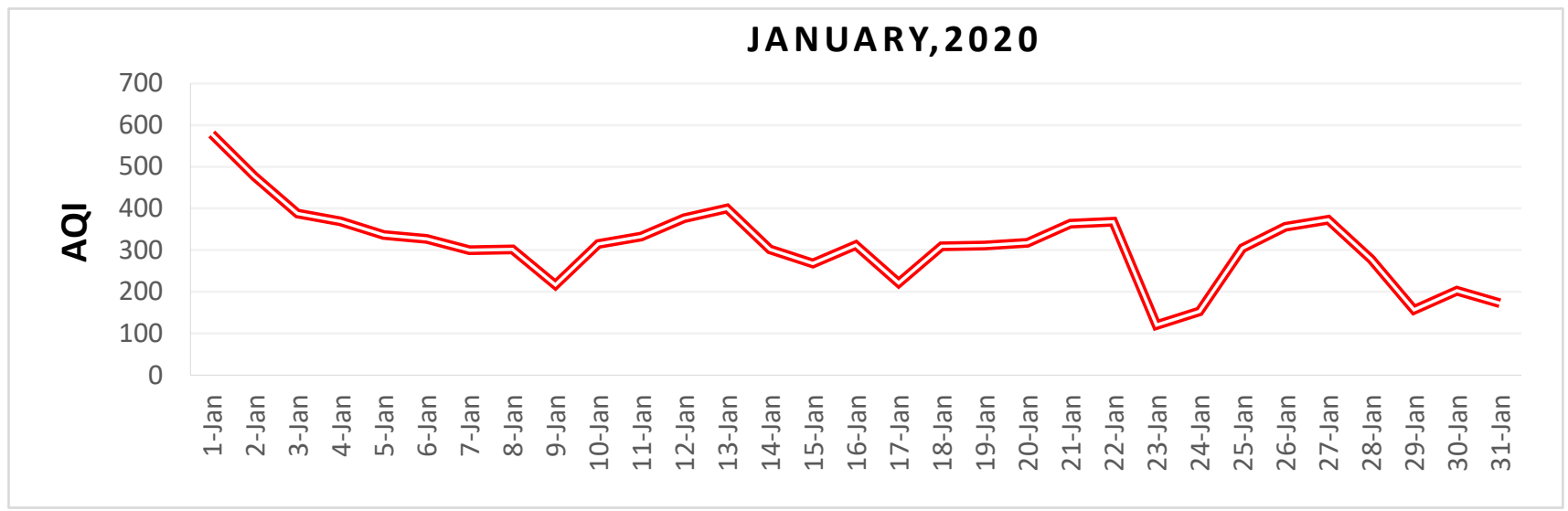

Fig. 4(A). AQI for Delhi during January 2020.

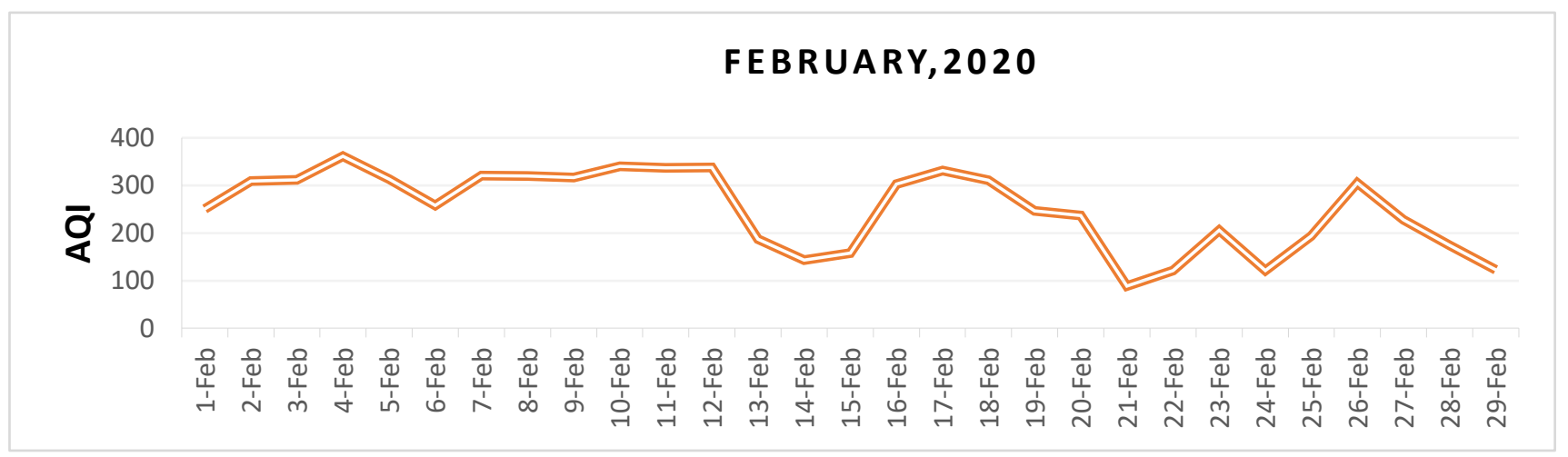

Fig. 4(B). AQI for Delhi during February 2020. 


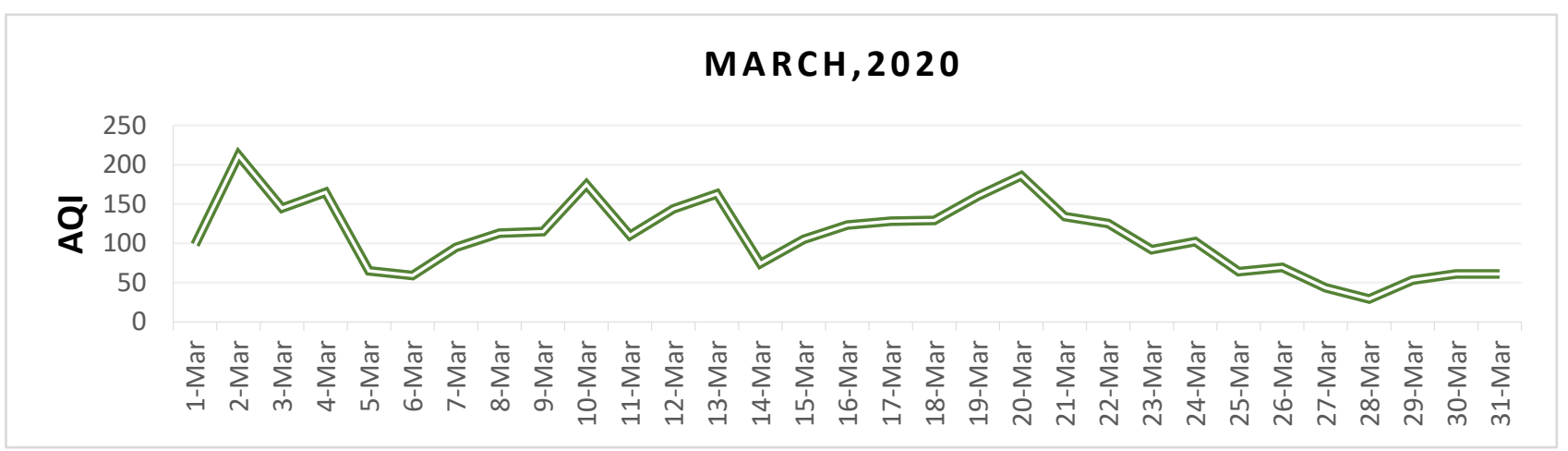

Fig. 4(C). AQI for Delhi during March 2020.

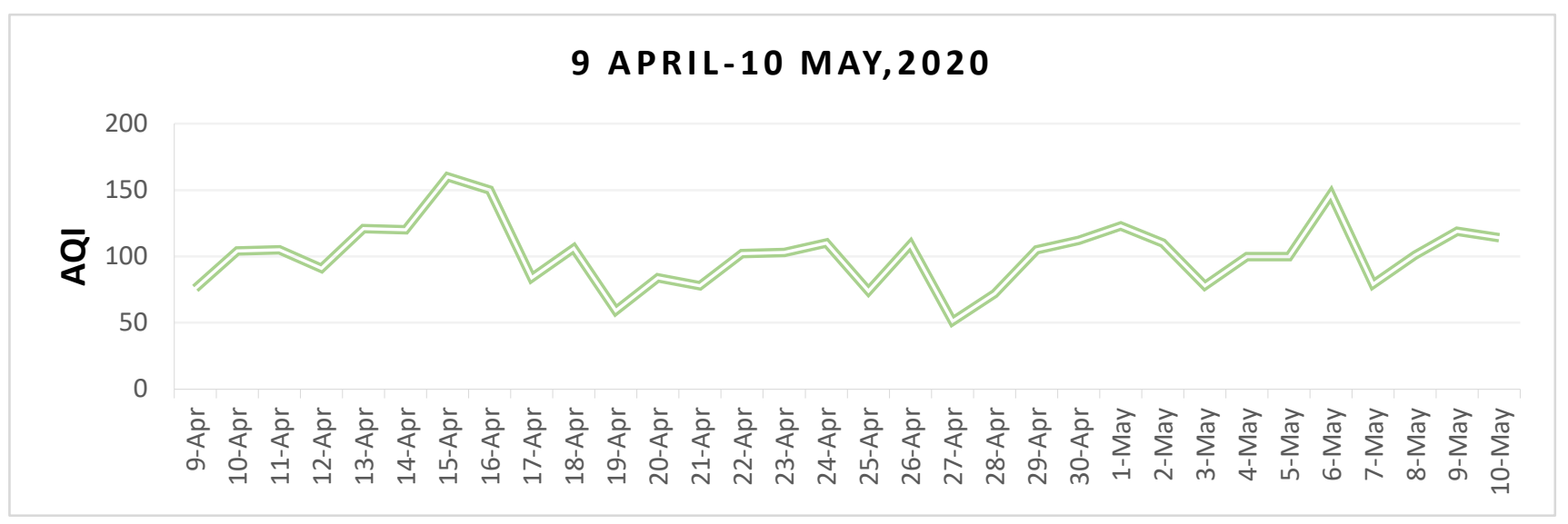

Fig. 4(D). AQI for Delhi during 9 April-10 May 2020.

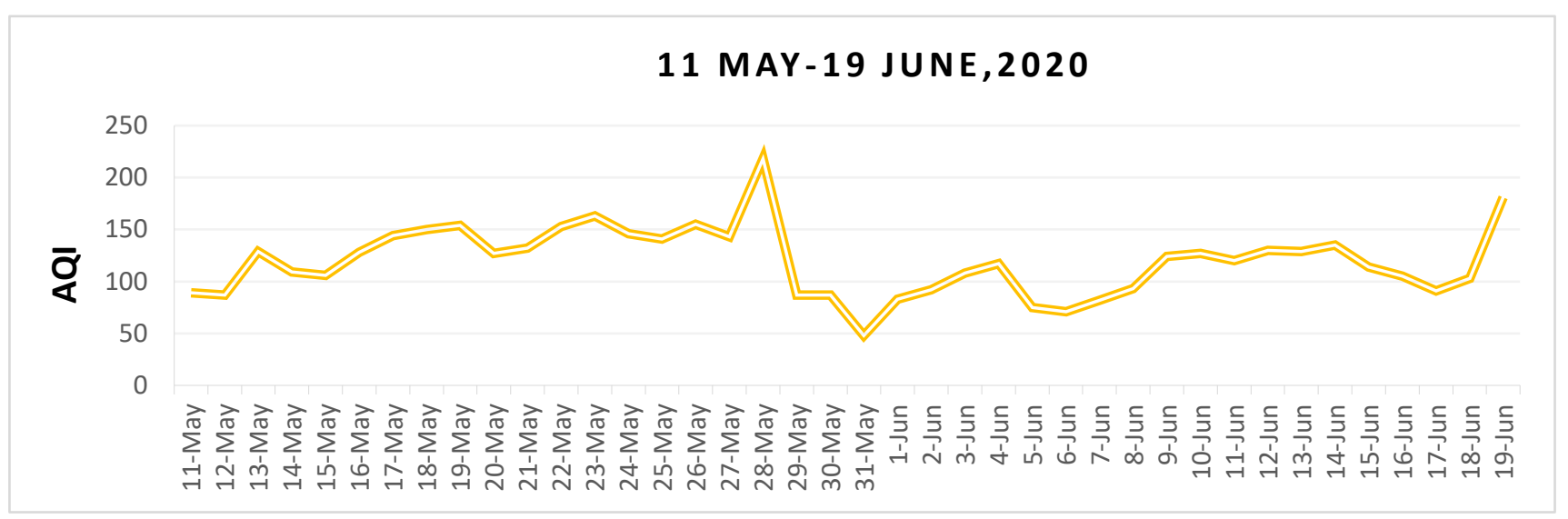

Fig. 4(E). AQI for Delhi during 11 May-19 June 2020.

standard deviation of 45.61 . The maximum, minimum, and average values of March AQls were $58.73 \%, 32.58 \%, 43.8 \%$ lower than the corresponding values of February 2020.

As shown in Fig. 4(D), the maximum AQI value recorded during the period 9 April-10 May 2020 was 160 while the minimum value was 59 and the average value was 101.46 with a standard deviation of 24.64 for the city of Delhi. In comparison with the maximum, minimum, and average values of AQIs of March 2020, the corresponding values of AQIs recorded from 9 April-10 May were $24.52 \%$ lower, $3.5 \%$ higher, and $7.4 \%$ lower.

As shown in Fig. 4(E), the maximum AQI value recorded in Delhi for the period 11 May-19 June 2020 was 218 while the minimum value was 48 and the average value was 119.4 with a standard 
deviation of 33.04. In comparison with the maximum, minimum, and average values of AQIs of 9 April-10 May 2020 period, the corresponding values of AQIs recorded during 11 May-19 June values were $36.25 \%$ higher, $18.64 \%$ lower, and $17.68 \%$ higher. The relaxation in the epidemic prevention and control actions during 9 April-10 May 2020 led to the weakening of air quality in Delhi vis-à-vis the upward movement of average AQI.

\subsection{AQI Class Distribution: Delhi}

As a result of the change in the concentrations of the different pollutants, the AQI classes prevailed in Delhi during the periods January, February, March, 9 April-10 May, and 11 May-19 June 2020 had shown a new pattern as evident from Figs. 5(A), 5(B), 5(C), 5(D) and 5(E). This

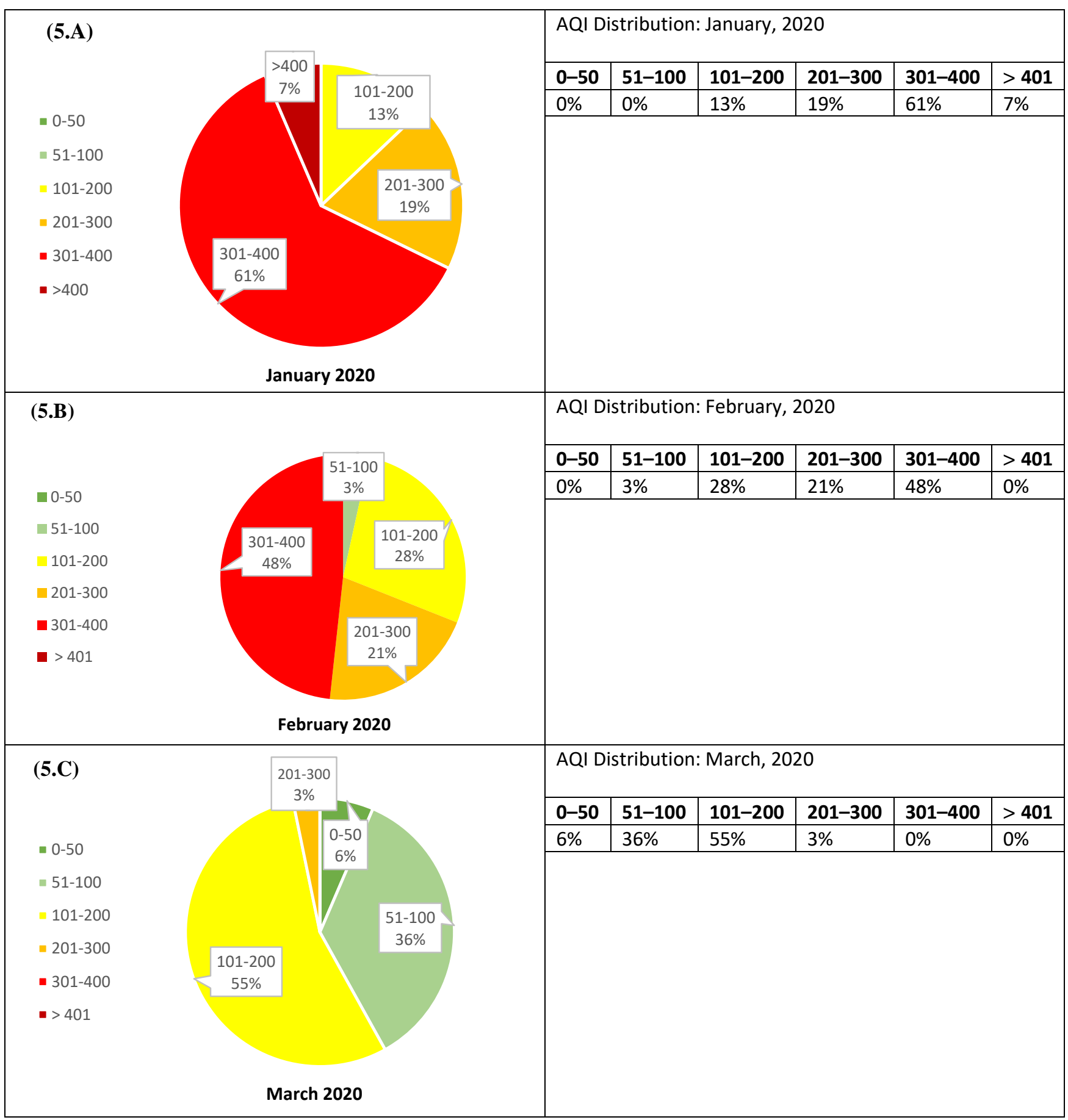

Fig. 5. The distribution of six AQI classes of Delhi. 


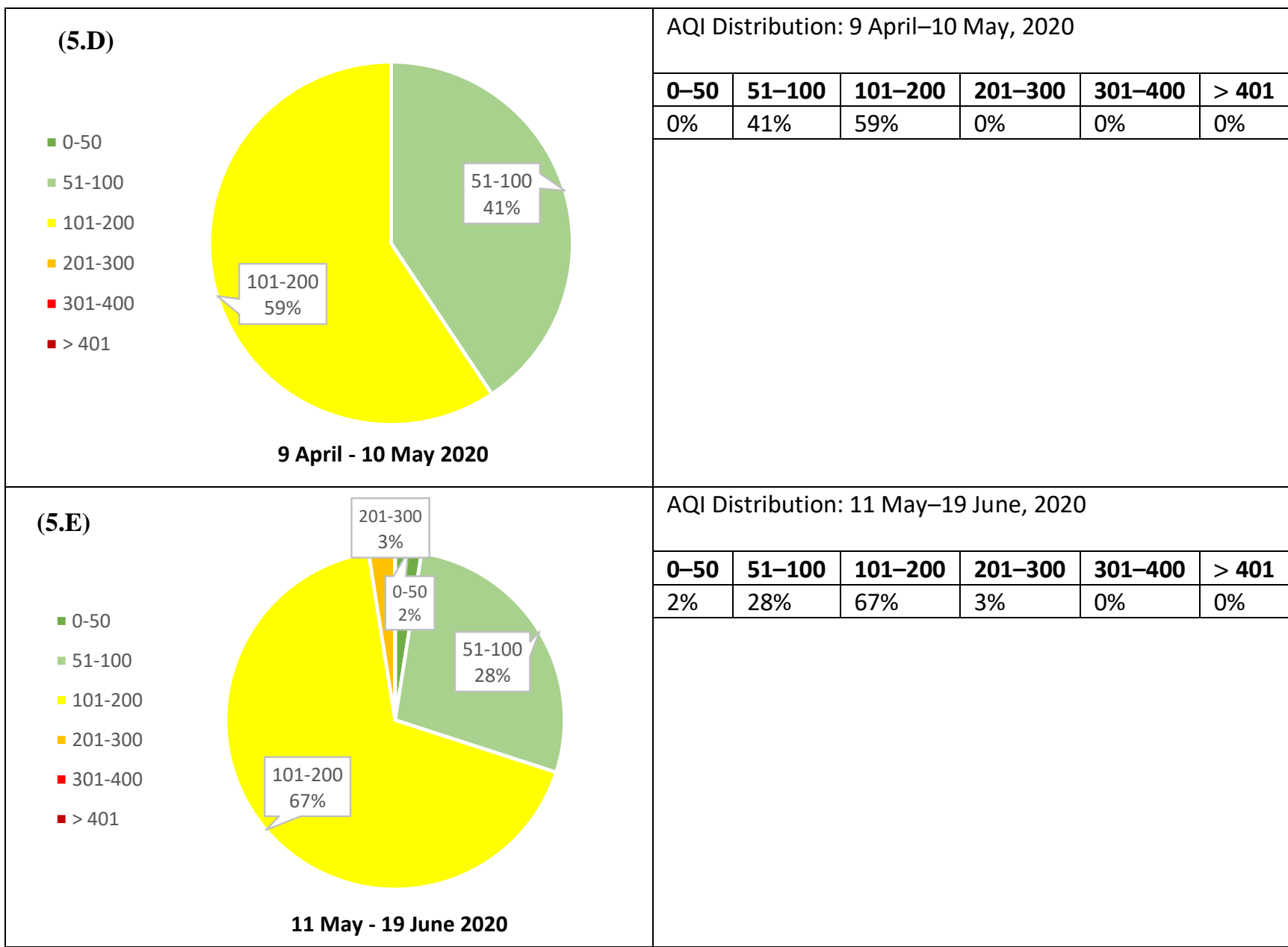

Fig. 5. (continued).

study found that Delhi experienced AQI classes I, II, III, IV, V, and VI in the proportion of $0 \%, 0 \%$, $13 \%, 19 \%, 61 \%$, and 7\% respectively during January 2020 as indicated in Fig. 5(A). The January distribution of AQIs indicates a severe air quality problem for the city as $87 \%$ of the time the city found itself in the IV, V, and VI classes of AQI. The distribution of AQI classes in Delhi underwent further changes in February with $0 \%, 3 \%, 28 \%, 21 \%, 48 \%$, and $0 \%$ in the classes I, II, III, IV, V, and $\mathrm{VI}$ respectively indicating somewhat betterment in the air pollution status as shown in Fig. 5(B). Fig. 5(C) indicated that during March 2020 there were AQI classes I, II, III, IV, V, and VI in the proportion of $6 \%, 36 \%, 55 \%, 3 \%, 0 \%$, and $0 \%$ respectively. In other words, $97 \%$ of the time the city found itself in the AQI classes I, II, and III only. During the peak COVID-19 period (9 April-10 May), the AQI classes I, II, III, IV, V, and VI were distributed in the proportion of $0 \%, 41 \%, 59 \%$, $0 \%, 0 \%$, and $0 \%$ respectively for Delhi city as indicated in Fig. 5(D). It can be understood, therefore, that during the peak COVID-19 period there were only two AQI classes, i.e., class II and class III which covered the whole AQIs of Delhi indicating a marked improvement in the city level pollution standard. Further, during 11 May-19 June period, AQI classes I, II, III, IV, V, and VI were in the proportion of $2.5 \%, 27.5 \%, 67.51 \%, 2.5 \%, 0 \%$, and $0 \%$ respectively indicating that the combined proportions of classes I, II and III decreased from previous $100 \%$ to $97.5 \%$ in the current period as shown in Fig. 5(E). In a sense, it indicates the beginning of air quality deterioration with somewhat corresponding relaxation in the strict epidemic prevention and control actions.

\subsection{AQI Level and Air Pollutants}

The proportion of the cumulative contribution of different pollutants in respective AQI classes prevailed in Delhi during different phases of the COVID-19 outbreak, which have been calculated out and placed in Tables 5(A) and 5(B) below. Table 5(A) indicates that during January 2020, Delhi 
Table 5(A). Contribution of different pollutants in AQI in Delhi: January and February 2020.

\begin{tabular}{|c|c|c|c|c|c|c|c|c|c|c|c|c|c|c|}
\hline \multirow{2}{*}{$\begin{array}{l}\text { AQI } \\
\text { Class }\end{array}$} & \multicolumn{7}{|c|}{ January 2020 (in \%) (31 days) } & \multicolumn{7}{|c|}{ February 2020 (in \%) (28 days) } \\
\hline & Days & $\mathrm{PM}_{2.5}$ & $\mathrm{PM}_{10}$ & $\mathrm{NO}_{2}$ & $\mathrm{SO}_{2}$ & $\mathrm{CO}$ & $\mathrm{O}_{3}$ & Days & $\mathrm{PM}_{2.5}$ & $\mathrm{PM}_{10}$ & $\mathrm{NO}_{2}$ & $\mathrm{SO}_{2}$ & $\mathrm{CO}$ & $\mathrm{O}_{3}$ \\
\hline 1 & 0 & $0 \%$ & $0 \%$ & $0 \%$ & $0 \%$ & $0 \%$ & $0 \%$ & 0 & $0 \%$ & $0 \%$ & $0 \%$ & $0 \%$ & $0 \%$ & $0 \%$ \\
\hline II & 0 & $0 \%$ & $0 \%$ & $0 \%$ & $0 \%$ & $0 \%$ & $0 \%$ & 1 & $20 \%$ & $33 \%$ & $21 \%$ & $6 \%$ & $0 \%$ & $20 \%$ \\
\hline III & 4 & $23 \%$ & $42 \%$ & $19 \%$ & $5 \%$ & $0 \%$ & $11 \%$ & 8 & $20 \%$ & $44 \%$ & $16 \%$ & $6 \%$ & $0 \%$ & $14 \%$ \\
\hline IV & 6 & $29 \%$ & $44 \%$ & $18 \%$ & $4 \%$ & $0 \%$ & $5 \%$ & 6 & $22 \%$ & $48 \%$ & $17 \%$ & $4 \%$ & $0 \%$ & $9 \%$ \\
\hline V & 19 & $32 \%$ & $47 \%$ & $14 \%$ & $3 \%$ & $0 \%$ & $3 \%$ & 14 & $27 \%$ & $46 \%$ & $16 \%$ & $4 \%$ & $0 \%$ & $7 \%$ \\
\hline VI & 2 & $38 \%$ & $49 \%$ & $9 \%$ & $2 \%$ & $0 \%$ & $2 \%$ & 0 & $0 \%$ & $0 \%$ & $0 \%$ & $0 \%$ & $0 \%$ & $0 \%$ \\
\hline
\end{tabular}

Table 5(B). Contribution of different pollutants in AQI in Delhi: March, 9 April-10 May and 11 May-19 June, 2020.

\begin{tabular}{|c|c|c|c|c|c|c|c|c|c|c|c|c|c|c|c|c|c|c|c|c|c|}
\hline \multirow{2}{*}{$\begin{array}{l}\text { AQI } \\
\text { Class }\end{array}$} & \multicolumn{7}{|c|}{ March, 2020 (in \%) (31 days) } & \multicolumn{7}{|c|}{9 April-10 May, 2020 (in \%) (30 days) } & \multicolumn{7}{|c|}{11 May-19 June, 2020 (in \%) (40 days) } \\
\hline & Days & $\mathrm{PM}_{2.5}$ & $\mathrm{PM}_{10}$ & $\mathrm{NO}_{2}$ & $\mathrm{SO}_{2}$ & $\mathrm{CO}$ & $\overline{\mathrm{O}_{3}}$ & Days & $\mathrm{PM}_{2.5}$ & $\mathrm{PM}_{10}$ & $\mathrm{NO}_{2}$ & $\mathrm{SO}_{2}$ & $\mathrm{CO}$ & $\overline{\mathrm{O}_{3}}$ & Days & $\mathrm{PM}_{2.5}$ & $\mathrm{PM}_{10}$ & $\mathrm{NO}_{2}$ & $\mathrm{SO}_{2}$ & $\mathrm{CO}$ & $\mathrm{O}_{3}$ \\
\hline 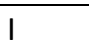 & 2 & 17 & 32 & 6 & 17 & 0 & 28 & 0 & 0 & 0 & 0 & 0 & 0 & 0 & 1 & 12 & 27 & 11 & 13 & 0 & 37 \\
\hline II & 11 & 17 & 36 & 15 & 11 & 0 & 21 & 13 & 14 & 36 & 6 & 11 & 0 & 33 & 11 & 14 & 36 & 10 & 10 & 0 & 30 \\
\hline III & 17 & 20 & 46 & 13 & 8 & 0 & 14 & 19 & 16 & 44 & 6 & 9 & 0 & 25 & 27 & 15 & 46 & 10 & 8 & 0 & 21 \\
\hline IV & 1 & 22 & 45 & 16 & 6 & 0 & 11 & 0 & 0 & 0 & 0 & 0 & 0 & 0 & 1 & 7 & 66 & 4 & 5 & 0 & 17 \\
\hline V & 0 & 0 & 0 & 0 & 0 & 0 & 0 & 0 & 0 & 0 & 0 & 0 & 0 & 0 & 0 & 0 & 0 & 0 & 0 & 0 & 0 \\
\hline VI & 0 & 0 & 0 & 0 & 0 & 0 & 0 & 0 & 0 & 0 & 0 & 0 & 0 & 0 & 0 & 0 & 0 & 0 & 0 & 0 & 0 \\
\hline
\end{tabular}

had four days of class III AQIs, six days of IV AQIs, nineteen days of class V AQIs, and two days of VI AQIs while classes I and II did not occur. The predominant air pollutants for the AQI class III, in order of their contributions, were $\mathrm{PM}_{10}(42 \%), \mathrm{PM}_{2.5}(23 \%), \mathrm{NO}_{2}(19 \%), \mathrm{O}_{3}(11 \%)$, and $\mathrm{SO}_{2}(5 \%)$. The predominant air pollutants for the AQI class IV, in order of their contributions, were $\mathrm{PM}_{10}$ $(44 \%), \mathrm{PM}_{2.5}(29 \%), \mathrm{NO}_{2}(18 \%), \mathrm{O}_{3}(5 \%)$, and $\mathrm{SO}_{2}(4 \%)$. Contribution of pollutants for the AQI class $\mathrm{VI}$, under which the city spent the lowest number of days, i.e., two days were (in order of contribution) $\mathrm{PM}_{10}(49 \%), \mathrm{PM}_{2.5}(38 \%), \mathrm{NO}_{2}(9 \%), \mathrm{O}_{3}(2 \%)$, and $\mathrm{SO}_{2}(2 \%)$. The critical point to be noticed that $\mathrm{PM}_{10}$ and $\mathrm{PM}_{2.5}$ were the pivotal pollutants in terms of their cumulative contribution to the AQI classes before the onset of the COVID-19 epidemic.

Table 5(A) further reveals that during February 2020, Delhi experienced fifteen days of class I to IV AQI levels which were ten days during January 2020, indicating an improvement in air quality. The predominant indicatory air pollutants for each of $A Q I$ were Class I: $\mathrm{PM}_{2.5}(4.8 \%)$ (followed by $\mathrm{PM}_{10}(4.4 \%), \mathrm{O}_{3}(0.8 \%)$, and $\mathrm{CO}(0.4 \%)$ ), Class II: $\mathrm{PM}_{10}(33 . \%)$ (followed by $\mathrm{PM}_{2.5}$ (20\%), $\mathrm{NO}_{2}(21 \%), \mathrm{O}_{3}(20 \%)$ and $\mathrm{SO}_{2}(6 \%)$ ), Class III: $\mathrm{PM}_{10}(44 \%)$ (followed by $\mathrm{PM}_{2.5}(20 \%), \mathrm{NO}_{2}$ (16\%), $\mathrm{O}_{3}(14 \%)$ and $\mathrm{SO}_{2}(6 \%)$ ), Class IV: $\mathrm{PM}_{10}(48 \%)$ (followed by $\mathrm{PM}_{2.5}(22 \%), \mathrm{NO}_{2}(17 \%), \mathrm{O}_{3}(9 \%)$ and $\mathrm{SO}_{2}(4 \%)$ ), respectively. The Class I and VI AQIs did not occur. Interesting to note that, $\mathrm{PM}_{10}$ and $\mathrm{O}_{3}$ contributions to AQIs comparatively increased and strengthened during February than in January 2020.

Table 5(B) reveals the change Delhi experienced in terms of the indicatory air pollutants constituting the AQIs at the introduction of lockdown during March 2020 and after that. The city witnessed, possibly after many years, class I AQI level of 2 days followed by 11 days of class II AQI level, 17 days of class III AQI level, and only one day of class IV AQI level during March 2020 while classes $\mathrm{V}$ and $\mathrm{VI}$ did not occur. The predominant indicatory air pollutants for the class I AQIs, in order of their contributions, was $\mathrm{PM}_{10}(32 \%), \mathrm{O}_{3}(28 \%), \mathrm{PM}_{2.5}(17 \%), \mathrm{SO}_{2}(17 \%)$, and $\mathrm{NO}_{2}(6 \%)$. Almost the same pattern followed for AQI class II and III of March but with increased contribution of $\mathrm{PM}_{10}$ to the tune of $36 \%$ and $46 \%$ respectively and decreased contribution of $\mathrm{O}_{3}$ of $21 \%$ and $14 \%$ respectively. Interesting to note here that as $\mathrm{NO}_{2}$ contributions maintained a somewhat increasing trend and $\mathrm{O}_{3}$ contributions had a decreasing trend as AQI classes moved from I to IV showing the inverse relationship between $\mathrm{NO}_{2}$ and $\mathrm{O}_{3}$ in the absence of sufficient VOC in the environment of Delhi under lockdown condition (Guo et al., 2019).

Table 5(B) also reveals the behavior of different pollutants during the peak of the COVID-19 period, i.e., 9 April-10 May 2020 in Delhi. The city witnessed a long stretch of 13 days under class II AQI level followed by 19 days under class III level while classes I, IV, V, and VI did open 
their account at all. The predominant air pollutants for the AQI class II, in order of their contributions, were $\mathrm{PM}_{10}(36 \%), \mathrm{O}_{3}(33 \%), \mathrm{PM}_{2.5}(14 \%), \mathrm{SO}_{2}(11 \%)$, and $\mathrm{NO}_{2}(6 \%)$. Again, the predominant air pollutants for the AQI class III, in order of their contributions, were $\mathrm{PM}_{10}(44 \%), \mathrm{O}_{3}(25 \%) \mathrm{PM}_{2.5}$ $(16 \%), \mathrm{SO}_{2}(9 \%)$, and $\mathrm{NO}_{2}(6 \%)$. The pattern indicates that for 30 days (9 April-10 May), though Delhi was experiencing comparatively favorable AQI classes (class II and III only) the dominance of $\mathrm{PM}_{10}$ in general and $\mathrm{O}_{3}$, in particular, had the potential to create health hazards. This point is distinguished from the point of view that $\mathrm{O}_{3}$ induced health effects include chest pain, coughing, throat irritation, and airway inflammation, which in turn could enhance COVID-19 induced criticalities as well.

The Table 5(B) also shows that during 40 days (11 May-19 June), which include the time of initiation of unlocking operation, Delhi had four AQI classes, i.e., class I (1 day), class II, (11 days), class III ( 27 days) and class IV (1 day). The predominant air pollutants for the AQI class I, in order of their contributions, were $\mathrm{O}_{3}(37 \%), \mathrm{PM}_{10}(27 \%), \mathrm{SO}_{2}(13 \%), \mathrm{PM}_{2.5}(12 \%)$, and $\mathrm{NO}_{2}(11 \%)$. The predominant air pollutants for the AQI class II, in order of their contributions, were $\mathrm{PM}_{10}(36 \%)$, $\mathrm{O}_{3}(30 \%), \mathrm{PM}_{2.5}(14 \%), \mathrm{NO}_{2}(10 \%)$, and $\mathrm{SO}_{2}(10 \%)$. Contributions of pollutants for the AQI class III, in order of contribution, were $\mathrm{PM}_{10}(46 \%), \mathrm{O}_{3}(21 \%), \mathrm{PM}_{2.5}(15 \%), \mathrm{NO}_{2}(10 \%)$, and $\mathrm{SO}_{2}(8 \%)$. Contributions of pollutants for the AQI class IV, in order of contribution, were $\mathrm{PM}_{10}(66 \%), \mathrm{O}_{3}(17 \%)$, $\mathrm{PM}_{2.5}(7 \%), \mathrm{SO}_{2}(5 \%)$ and $\mathrm{NO}_{2}$ (4\%). An important point to be noticed here that during 40 days (11 May-19 June), accommodating the AQI class of $1, \mathrm{II}, \mathrm{III}$, and IV, the $\mathrm{O}_{3}$ contributions were $37 \%$. $30 \%, 21 \%$, and $17 \%$ respectively showing the dominance of $\mathrm{O}_{3}$ as the indicatory air pollutants in these AQIs.

\subsection{COVID-19 and its Interactions with Environmental Parameters of Delhi}

At the inception of the COVID-19 outbreak, without any availability of vaccination or medication, countries resorted to a lockdown strategy to break down the COVID-19 infection cycle through social distancing. Entering into the community transmission phase, characterized by infections spreading in public without easy detection of source, highly polluted city like Delhi would require a more in-depth understanding of the behavior of criteria pollutants $\left(\mathrm{PM}_{2.5}, \mathrm{O}_{3}, \mathrm{NO}_{2}\right.$, and $\mathrm{SO}_{2}$ ) and meteorological parameters (temperature and $\mathrm{RH}$ ) concerning the spread of infection. Two different periods have been analyzed here, one; from 1 March to 10 May marked by inception and rapid increase of disease with strict enforcement of epidemic control measures, and two; from 11 May-19 June 2020 marked by a rapid increase of the diseases but with 'unlock' operation in force. The descriptive statistics of COVID-19 daily infection cases, the air pollutants, and the meteorological variables during these two periods can be seen in Table 6.

The correlations among the data variables are shown in Table 7. New COVID-19 cases per day maintained negative correlations with variables like $\mathrm{PM}_{2.5}, \mathrm{NO}_{2}$, and $\mathrm{RH}$ but positive correlations with $\mathrm{O}_{3}$ and temperature during the 1 March-10 May 2020 period. During the 11 May-19 June period, only $\mathrm{RH}$ had a positive correlation with COVID-19 cases per day while $\mathrm{O}_{3}$ and $\mathrm{SO}_{2}$ had negative correlations as can be seen from Table 7 .

\subsection{Relative Humidity, Temperature and COVID-19}

Recent research has highlighted that environmental factors, especially temperature and $\mathrm{RH}$, are essential factors in responding to viral infections in the respiratory tract through activating

Table 6. Descriptive Statistics of the data variables of Delhi $(N=111)$.

\begin{tabular}{|c|c|c|c|c|c|c|}
\hline \multirow{2}{*}{ Variables } & \multicolumn{3}{|c|}{1 March-10 May } & \multicolumn{3}{|c|}{11 May-19 June, 2020} \\
\hline & Min & Max & Mean & Min & Max & Mean \\
\hline $\mathrm{PM}_{2.5}\left(\mu \mathrm{g} \mathrm{m}^{-3}\right)$ & 15.2 & 93.6 & 42.4 & 15.41 & 76.10 & 42.15 \\
\hline $\mathrm{NO}_{2}(\mathrm{ppb})$ & 6.5 & 67.1 & 23.9 & 13.56 & 53.93 & 27.31 \\
\hline $\mathrm{SO}_{2}(\mathrm{ppb})$ & 14.8 & 42.3 & 23.3 & 12.55 & 44.64 & 24.05 \\
\hline $\mathrm{O}_{3}(\mathrm{ppb})$ & 25.4 & 108.3 & 56.3 & 30.36 & 92.54 & 66.59 \\
\hline Temperature $\left({ }^{\circ} \mathrm{C}\right)$ & 15.7 & 33.6 & 25.4 & 25.94 & 38.44 & 33.21 \\
\hline $\mathrm{RH}(\%)$ & 25 & 90.3 & 53.5 & 17.1 & 73.5 & 42.85 \\
\hline COVID-19 cases/day & 0 & 448 & 98 & 299 & 3137 & 1157 \\
\hline
\end{tabular}


Table 7. Correlations among the data variables of Delhi.

\begin{tabular}{llllllll}
\hline COVID-19/day & Pearson Correlation & $\mathrm{PM}_{2.5}$ & $\mathrm{NO}_{2}$ & $\mathrm{SO}_{2}$ & $\mathrm{O}_{3}$ & Temperature $\left({ }^{\circ} \mathrm{C}\right)$ & $\mathrm{RH}(\%)$ \\
\hline 1March-10 May, & Coefficient & $-0.301^{*}$ & $-0.472^{* *}$ & 0.133 & $0.670^{* *}$ & $0.548^{* *}$ & $-0.341^{* *}$ \\
2020 & $\mathrm{~N}$ & 71 & 71 & 71 & 71 & 71 & 71 \\
11 May-19 June, & Coefficient & -0.245 & -0.091 & $-0.674^{* *}$ & $-0.402^{*}$ & 0.098 & $0.476^{* *}$ \\
2020 & $\mathrm{~N}$ & 40 & 40 & 40 & 40 & 40 & 40 \\
\hline
\end{tabular}

**. Correlation is significant at the 0.01 level (2-tailed).

*. Correlation is significant at the 0.05 level (2-tailed).

the immune system of human beings (Falagas et al., 2008; Makinen et al., 2009). More importantly, studies have also revealed the role of temperature and humidity on respiratory virus stability and transmission rates (Moriyama et al., 2020). Fig. 6 below indicates that Delhi had an average RH of around $53.5 \%$ during 1 March-10 May 2020 while the maximum recorded as $90.3 \%$ and a minimum of $25 \%$. During this phase, the COVID-19 infection cases were also in the low ebb (average 98 cases per day) as can be seen from Fig. 6 and Table 6. The higher humid condition prevailed from 1 March-10 May also maintained a negative correlation with the daily COVID-19 cases, as indicated in Table 7. However, from 11 May-19 June 2020, when the average RH level in Delhi air was down to an average $42.85 \%$ with the maximum level stood at $73.5 \%$, and the minimum level as low as $17.1 \%$, it had a positive correlation with the COVID-19 infection cases. Fig. 6 and Table 6 also indicate that the COVID-19 infection increased to an average of 1157 cases per day during the 11 May-19 June 2020 period. Table 7, therefore, indicates the existence of a positive correlation between RH and daily COVID-19 infection cases when humidity level was comparatively low. Several studies in the past confirmed that air with low humidity levels might be an essential risk factor for respiratory infection diseases vis a vis increase in mortality rates (Barreca, 2012; Davis et al., 2016; Sajadi et al., 2020).

Fig. 7 indicates that Delhi had an average temperature of around $25.4^{\circ} \mathrm{C}$ during $1 \mathrm{March}-10$ May, with a maximum recorded as $33.6^{\circ} \mathrm{C}$ and a minimum of $15.7^{\circ} \mathrm{C}$. Again, from 11 May-19 June, the average temperature level went up to $33.21^{\circ} \mathrm{C}$ with the maximum level stood at $38.44^{\circ} \mathrm{C}$ and the minimum level as $25.94^{\circ} \mathrm{C}$. The comparatively low-temperature situation during 1 March-10 May 2020 was found to have a positive correlation (0.548) with the daily COVID-19 cases in Delhi while the comparatively high-temperature situation during 11 May-19 June found no significant correlation with the daily COVID-19 infection cases as revealed from Table 7. Therefore, in the case of Delhi, comparatively low RH and the low-temperature situation is found to be positively correlated with COVID-19 infection cases. However, it requires more studies to understand whether high $\mathrm{RH}$ and high temperature that prevails in other cities of India like Kolkata or Thai city Bangkok had any deterrent effect in the COVID-19 infection spread as the correlation analysis used here does not indicate any causality (Chan et al., 2011).

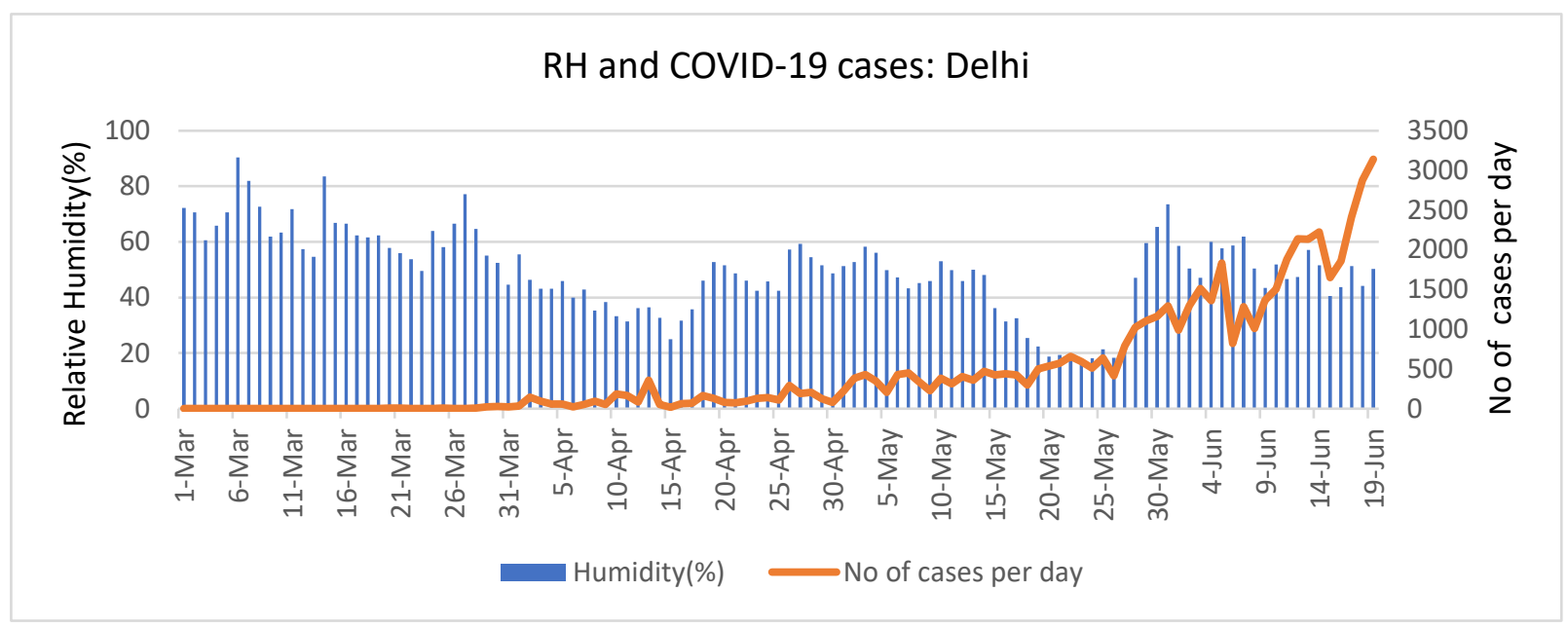

Fig. 6. RH of Delhi and confirmed cases. 


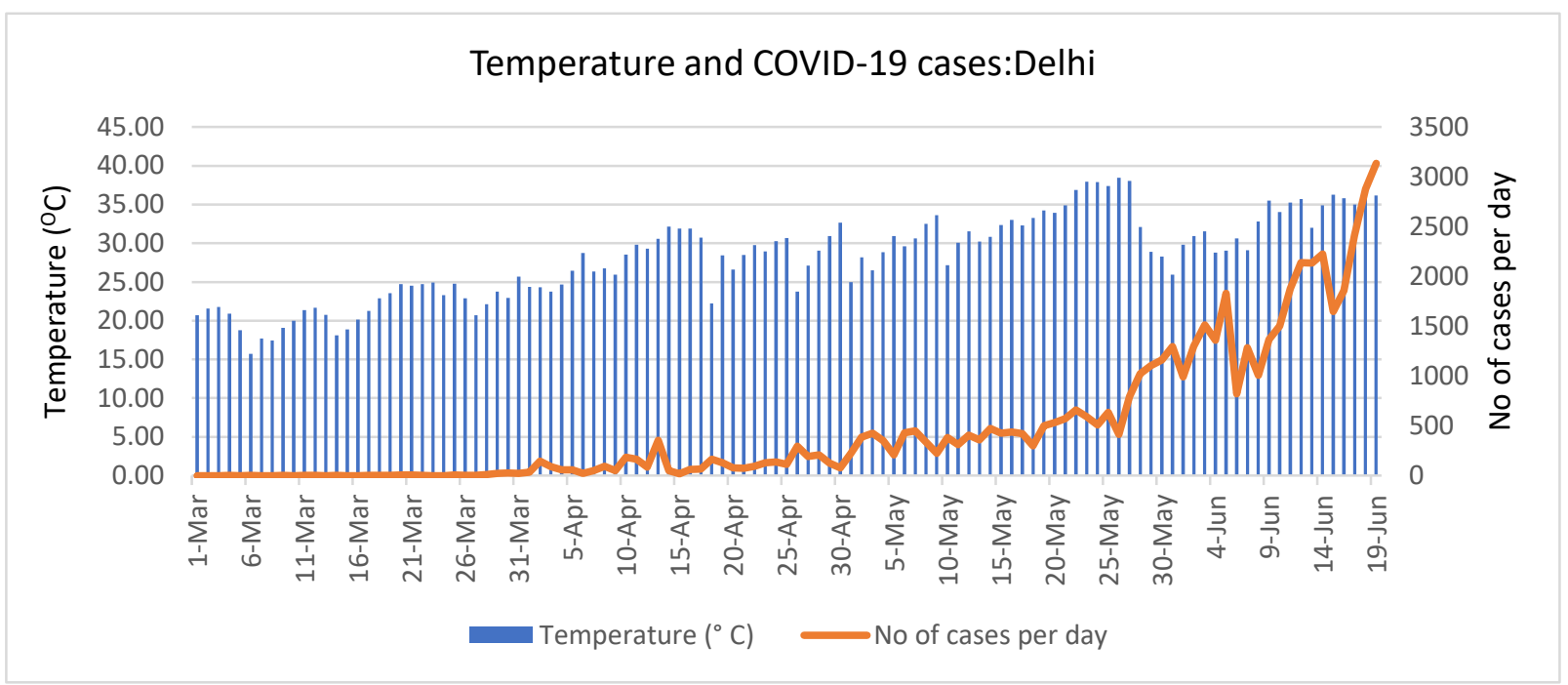

Fig. 7. Temperature of Delhi and confirmed cases.

\subsection{Nitrogen Dioxide and COVID-19}

As can be seen in Table 6 and Fig. 8 below that Delhi had an average $\mathrm{NO}_{2}$ of around $23.9 \mathrm{ppb}$ during1 March-10 April with a maximum recorded as $67.09 \mathrm{ppb}$ and a minimum of $6.5 \mathrm{ppb}$. After that, from 11 May-19 June, the city of Delhi had a marginal rise in $\mathrm{NO}_{2}$ level with an average of $27.31 \mathrm{ppb}$ while the maximum was $53.93 \mathrm{ppb}$ and the minimum was $13.56 \mathrm{ppb}$. Fig. 8 and Table 7 indicate that during phase 11 May-19 June, there was also a considerable rise of COVID-19 cases in Delhi. However, no significant correlation between $\mathrm{NO}_{2}$ and COVID-19 cases in Delhi could be established. However, a comparatively lower $\mathrm{NO}_{2}$ level from 1 March-10 April demonstrated a significant negative correlation with COVID-19 cases in Delhi, indicating lower $\mathrm{NO}_{2}$ presence in the air could be a COVID-19 deterrent. Earlier studies found that chronic exposure to high $\mathrm{NO}_{2}$ levels in the environment caused inflammation in the lungs, which could be a vital contributor to the high COVID-19 fatality rates (Ogen et al., 2020). Therefore, the non-significant correlation between the comparatively higher $\mathrm{NO}_{2}$ level and COVID-19 cases in the city of Delhi, as indicated in Fig. 8, opens a new area for further exploration.

\subsection{Sulphur Dioxide and COVID-19}

Delhi had an average $\mathrm{SO}_{2}$ level of $23.3 \mathrm{ppb}$ in the air from 1 March-10 May 2020 with maximum recoded as $67.1 \mathrm{ppb}$ and a minimum of $6.5 \mathrm{ppb}$ as can be seen from Table 6 and Fig. 9. For the period 11 May to 19 June, the average $\mathrm{SO}_{2}$ level marginally increased to $24.05 \mathrm{ppb}$ with a maximum of $44.64 \mathrm{ppb}$ and a minimum of $12.58 \mathrm{ppb}$ which shows a marginal change in the average $\mathrm{SO}_{2}$ concentration level in the city during the two phases under consideration. Therefore, it will be complicated to assess the role of $\mathrm{SO}_{2}$ with the number of daily COVID-19 confirmed cases found in Delhi at a comparative level between the two periods under consideration. However, the present study found that when the $\mathrm{SO}_{2}$ level marginally increased from 11 May-19 June, it had a significant negative correlation with (-0.402) COVID-19 cases in Delhi (Table 7 and Fig. 9). This finding is in alignment with an earlier study of 120 Chinese cities which found a negative association of $\mathrm{SO}_{2}$ with the number of daily COVID-19 confirmed cases (Zhu et al., 2020).

\subsection{Ozone and COVID-19}

As can be seen in Table 6 and Fig. 10 that Delhi had an average $\mathrm{O}_{3}$ level of $56.3 \mathrm{ppb}$ in the air from 1 March-10 May with a maximum recoded as $108.3 \mathrm{ppb}$ and a minimum of $25.4 \mathrm{ppb}$. During May 11-June 19, the average $\mathrm{O}_{3}$ level shot up to $66.59 \mathrm{ppb}$ while maximum and minimum level recorded as high as $92.54 \mathrm{ppb}$ and $30.36 \mathrm{ppb}$ respectively. As shown in Fig. 10 and Table 7 that daily new COVID-19 cases for the period 1 March-10 May exhibited significant positive correlations (0.670) with $\mathrm{O}_{3}$ but inverse correlations from 11 May-19 June, when $\mathrm{O}_{3}$ concentration was comparatively higher. Zoran et al. (2000) indicated that $\mathrm{O}_{3}$ had shown positive correlations with 
daily new COVID-19 cases in Milan, Italy while this study indicates that $\mathrm{O}_{3}$ possibly exhibits a positive correlation with new COVID-19 cases under the condition of comparatively low temperature and low humidity.

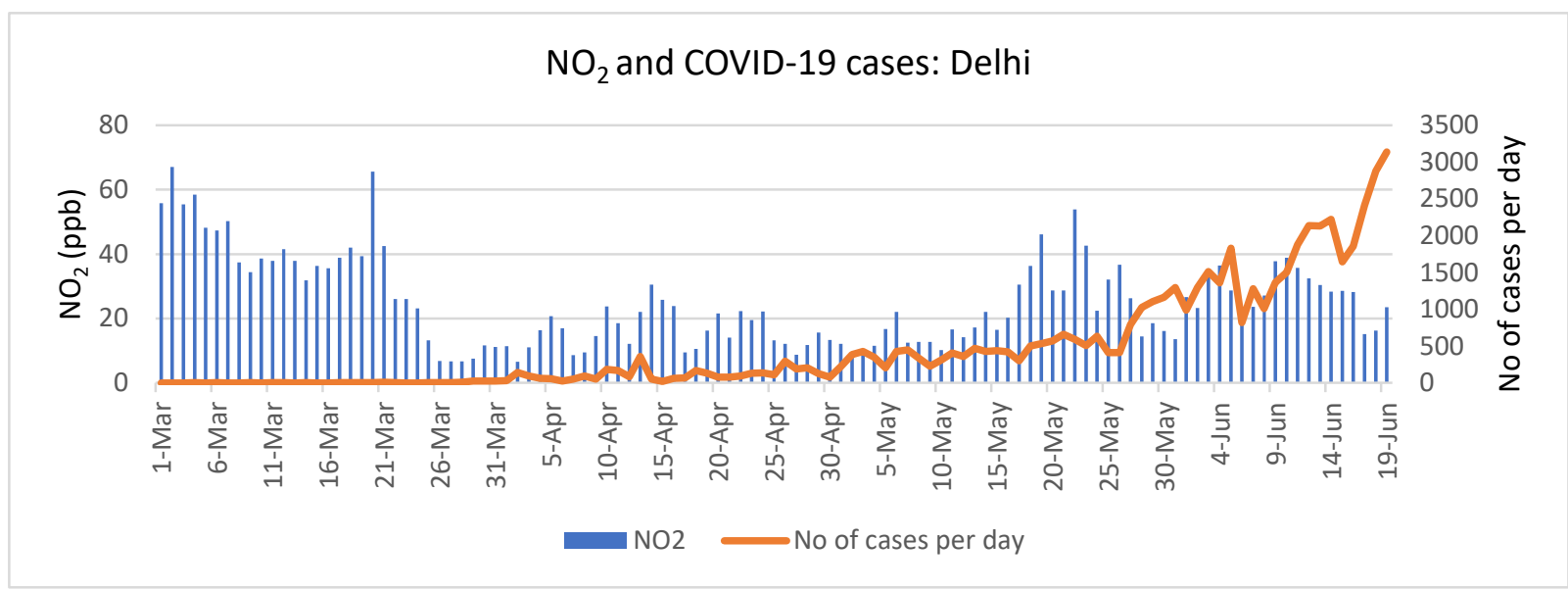

Fig. 8. $\mathrm{NO}_{2}$ of Delhi and confirmed cases.

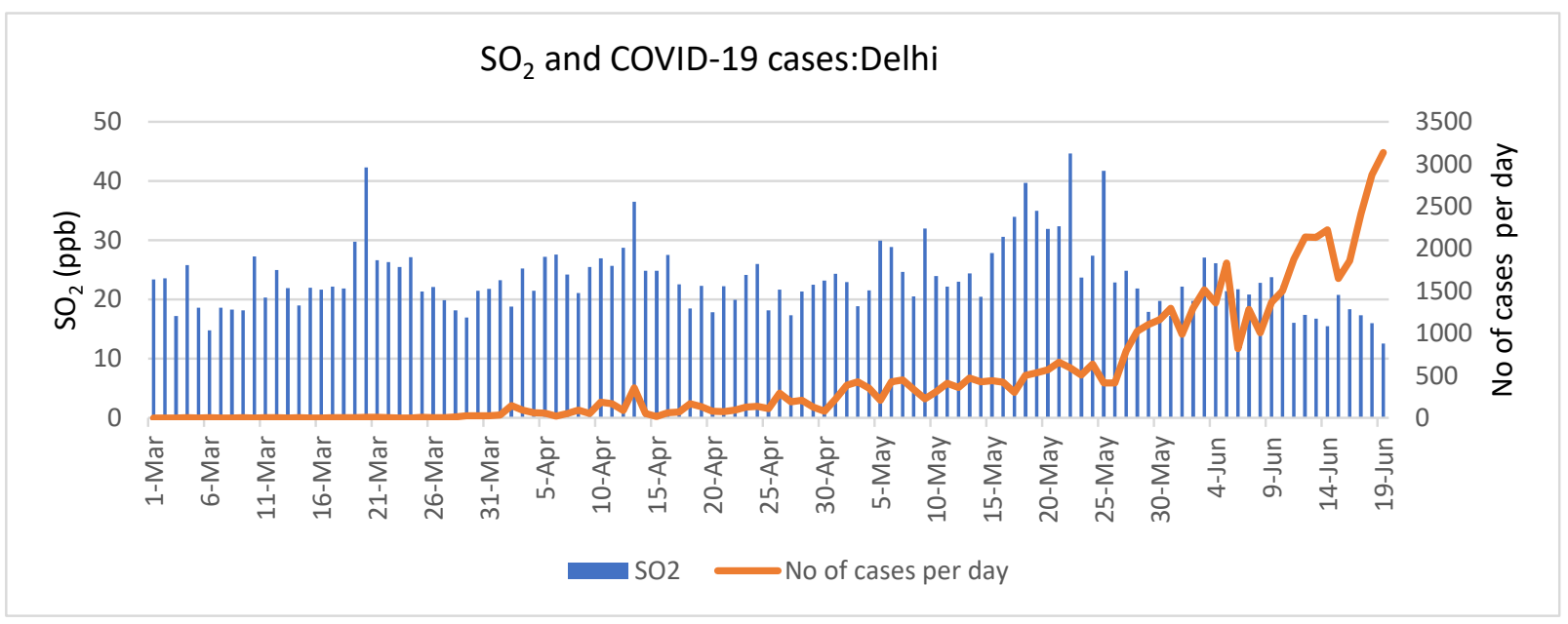

Fig. 9. $\mathrm{SO}_{2}$ of Delhi and confirmed cases.

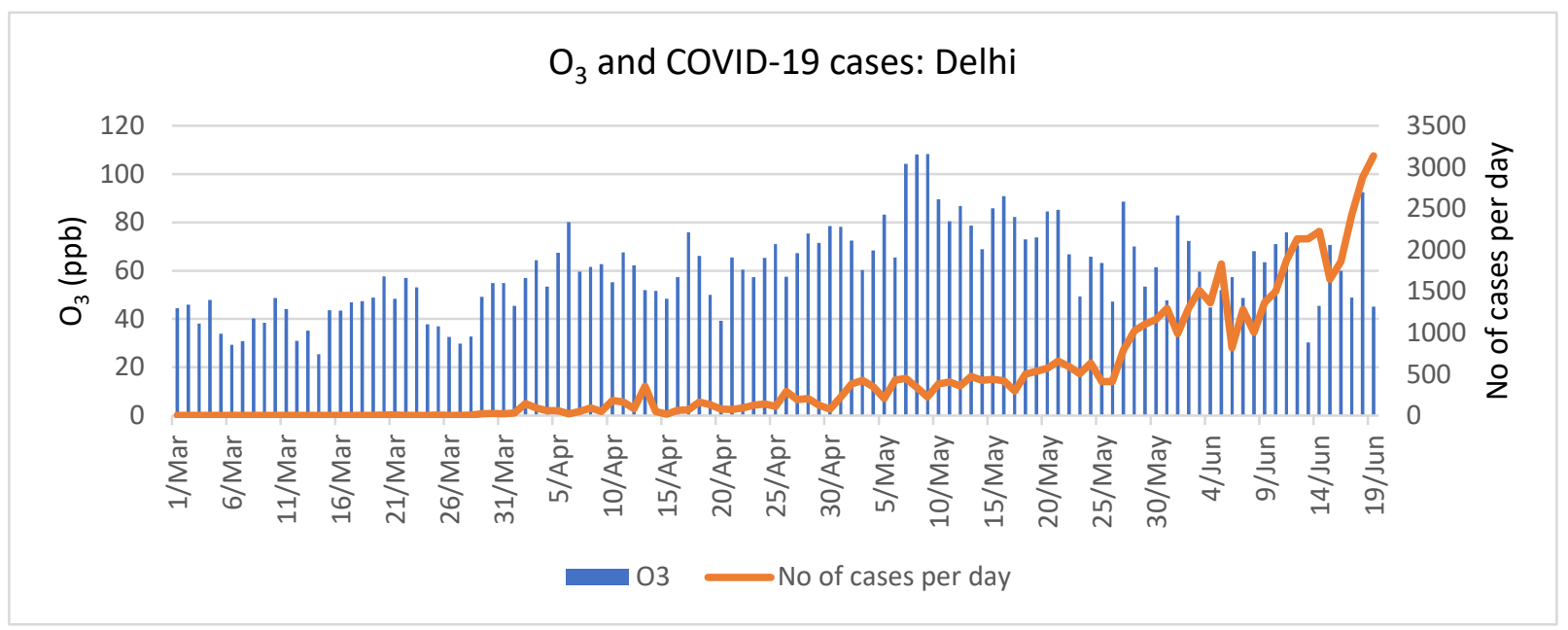

Fig. 10. $\mathrm{O}_{3}$ of Delhi and confirmed cases. 


\section{CONCLUSION AND POLICY IMPLICATIONS}

India is fighting hard to restrain and control the outbreak of COVID-19 in the country. Delhi is the frontrunner with the most infected cases per million population in the country. COVID-19 positive cases steadfastly increased from the first case surfaced on 4 March 2020 to 53,116 cases as of 19 June 2020 in the city with the coefficient of variation as high as $142.76 \%$.

Based on a time series analysis of the criteria pollutants, meteorological parameters, and COVID-19 data, covering five different periods of COVID-19 outbreak in Delhi, this study found that in-between January to 11 May-19 June 2020 period, the average concentration of air pollutants like $\mathrm{PM}_{2.5}, \mathrm{PM}_{10}, \mathrm{NO}_{2}$, and $\mathrm{CO}$ reduced drastically by $73.85 \%, 46.48 \%, 63.43 \%$, and $50.18 \%$ respectively. However, air pollutants like $\mathrm{O}_{3}$ and $\mathrm{SO}_{2}$ increased significantly by $217.33 \%$ and $57.58 \%$ respectively from January to 11 May-19 June 2020 period.

Just before the onset of the COVID-19 epidemic in Delhi (January and February 2020), the concentration level of the primary pollutants from vehicle emission ( $\mathrm{PM}, \mathrm{NO}_{2}$, and $\mathrm{CO}$ ) in the air was very high. After the lockdown policy, these pollutants decreased, but $\mathrm{PM}_{10}$ was still at a higher level than the NAAQS. $\mathrm{SO}_{2}$ concentration level, before and after the lockdown policy continued to rise in Delhi. The rise of $\mathrm{PM}_{10}$ could be due to open burning sources, from biomass, solid waste, and domestic cooking while the rise of $\mathrm{SO}_{2}$ could be attributed to a combination of long-distance transfer, power plant emissions in the vicinity, and biomass burning allowed even during the lockdown. The sharp rise of $\mathrm{O}_{3}$ in Delhi was due to accumulation in the atmosphere as not enough $\mathrm{NO}$ was there in the air to react with $\mathrm{O}_{3}$ to form $\mathrm{O}_{2}$.

The ups and downs of pollutants in the atmosphere had its effects on AQI levels experienced by the city and in the proportional cumulative contribution of different pollutants constituting the AQIs of Delhi. During January 2020, i.e., before the onset of the COVID-19 epidemic, Delhi had $61.29 \%$ of the days under AQI class $V$ thereby indicating high air pollution with possible respiratory illness to the people on prolonged exposure. $\mathrm{PM}_{10}$ and $\mathrm{PM}_{2.5}$ were pivotal pollutants in terms of their cumulative contribution to the AQI classes before the onset of the COVID-19 epidemic. During the peak COVID-19 phase (9 April-10 May 2020), though Delhi had improved AQI classes of II and III only, the pivotal pollutants in terms of their cumulative contribution to the AQI classes were $\mathrm{PM}_{10}$ and $\mathrm{O}_{3}$ indicating possible health hazards mainly due to higher level of $\mathrm{O}_{3}$ in air.

The study found that comparatively low RH and the low-temperature situation was significantly and positively correlated with the new COVID-19 infection cases in Delhi. However, it requires more studies to understand whether high $\mathrm{RH}$ and high temperature that prevails in other cities of the world had any deterrent effect in the COVID-19 infection spread. Comparatively lower $\mathrm{NO}_{2}$ levels in the air demonstrated a significant negative correlation with new COVID-19 cases in Delhi. In a similar line, when the average $\mathrm{SO}_{2}$ level in the air was marginally increased to $24.05 \mathrm{ppb}$, it had a significant negative correlation $(-0.402)$ with new COVID-19 cases in Delhi. Daily new COVID-19 cases of Delhi exhibited significant positive correlations (0.670) with $\mathrm{O}_{3}$ at around 56.3 ppb level, but inverse correlations during when average $\mathrm{O}_{3}$ concentration was comparatively higher at $66.59 \mathrm{ppb}$. Possibly $\mathrm{O}_{3}$ exhibits a positive correlation with new COVID-19 cases under the condition of comparatively low temperature and low humidity. Delhi and other cities of India are currently at a challenging phase of community transmission, and a full understanding of the association between COVID-19 and climate indicators will help them to check the diffusion of the disease by positioning correct counter-strategy in place. In this respect, some practical implications are coming out of the findings of the study. Firstly, during the winter months, Delhi's temperature comes down as low as 3 to 4 degrees Celsius. As low temperatures and low RH found to supportive of COVID-19 infection spread, the authority must prepare an anti-epidemic plan for the city if the disease continues to exist till the end of the current year and beyond. Secondly, the study has indicated that during a period (say, fortnight or month) the city can have a different combination of AQI classes based on different levels of stringency on mobility restrictions enforced. In addition, the predominance of different indicatory air pollutants also varied for the different combinations of AQIs. The authority now can selectively use lockdown as a strategy to have a desired pattern of AQIs which will be beneficial for restricting the disease to spread during different climatic conditions. Our findings have a few limitations as well. Further research, in this line, should 
consider data for criteria pollutants from all the ambient air quality monitoring stations of Delhi and for an extended period to have a better predictive effect of the findings. Finally, the study findings related to the correlation of air pollutants and meteorological variables with COVID-19 infection in the city are derived from statistical analysis and some amount of causal inference.

\section{ACKNOWLEDGMENTS}

This study was supported by the Graduate School Thesis Grant, Chulalongkorn University, Bangkok, Thailand. The authors also sincerely appreciate the Central Pollution Control Board (CPCB), and Central Meteorological Department, Delhi, for air pollution and meteorological information, respectively.

\section{SUPPLEMENTARY MATERIAL}

Supplementary data associated with this article can be found in the online version at https://doi.org/10.4209/aaqr.2020.07.0417

\section{REFERENCES}

Agarwal, A., Kaushik, A., Kumar, S., Mishra, R.K. (2020). Comparative study on air quality status in Indian and Chinese cities before and during the COVID-19 lockdown period. Air Qual. Atmos. Health 13, 1167-1178. https://doi.org/10.1007/s11869-020-00881-z

Al-Tawfiq, J.A., Zumla, A., Memish, Z.A. (2014). Travel implications of emerging corona viruses: SARS and MERS-CoV. Trav. Med. Infect. Dis. 12: 422-428. https://doi.org/10.1016/j.tmaid.20 14.06.007

Aman, M.A., Salman, M.S., Yunus, A.P. (2020). COVID-19 and its impact on environment: Improved pollution levels during the lockdown period - A case from Ahmedabad, India. Remote Sens. Appl.: Soc. Environ. 20, 100382. https://doi.org/10.1016/j.rsase.2020.100382

Babu, S.R., Rao, N.N., Kumar, S.V., Paul, S., Pani, S.K. (2020). Plausible Role of Environmental Factors on COVID-19 Transmission in the Megacity Delhi, India. Aerosol Air Qual. Res. 20: 2075-2084. https://doi.org/10.4209/aaqr.2020.06.0314

Barreca, A.I. (2012). Climate change, humidity, and mortality in the United States, J. Environ. Econ. Manag., 63, 19-34, https://doi.org/10.1016/j.jeem.2011.07.004

Bedi, J.S., Dhaka, P., Vijay, D., Aulakh, R.S., Gill, J.P.S. (2020). Assessment of Air Quality Changes in the Four Metropolitan Cities of India during COVID-19 Pandemic Lockdown. Aerosol Air Qual. Res. 20, 2062-2070. https://doi.org/10.4209/aaqr.2020.05.0209

Beig, G., Bano, S., Sahu, S.K., Anand, V., Korhale, N., Rathod, A., Yadav, R., Mangaraj, P., Murthy, B.S., Singh, S., Latha, R., Shinde, R. (2020). COVID-19 and environmental -weather markers: Unfolding baseline levels and veracity of linkages in tropical India. Environ. Res. 191, 110121. https://doi.org/10.1016/j.envres.2020.110121

Bera, B., Bhattacharjee, S., Shit, P.K., Sengupta, N., Saha, S. (2020). Significant impacts of COVID19 lockdown on urban air pollution in Kolkata (India) and amelioration of environmental health. Environ. Dev. Sustain. https://doi.org/10.1007/s10668-020-00898-5

Bilal., Bashir, M.F., Benghoul, M., Numan, U., Shakoor, A., Komal, B., Bashir, M.A., Bashir, M., Tan, D. (2020). Environmental pollution and COVID-19 outbreak: insights from Germany. Air Qual. Atmos. Health 13, 1385-1394. https://doi.org/10.1007/s11869-020-00893-9

Biswas, M.S., Ghude, S.D., Gurnale, D., Prabhakaran, T., Mahajan, A.S. (2019). Simultaneous observations of nitrogen dioxide, formaldehyde and ozone in the Indo-Gangetic Plain. Aerosol Air Qual. Res. 19, 1749-1764. https://doi.org/10.4209/aaqr.2018.12.0484

Cartenì. A., Di Francesco, L., Martino, M. (2020). How mobility habits influenced the spread of the COVID-19 pandemic: Results from the Italian case study. Sci. Total Environ. 741, 140489. https://doi.org/10.1016/j.scitotenv.2020.140489

Chameides, W.L., Fehsenfeld, F., Rodgers, M.O., Cardelino, C., Martinez, J., Parrish, D., Lonneman, W., Lawson, D.R., Rasmussen, R.A., Zimmerman, P., Greenberg, J., Middleton, P., Wang, T. 
(1992). Ozone precursor relationships in the ambient atmosphere. J. Geophys. Res. 97, 60376055. https://doi.org/10.1029/91JD03014

Chan, K.H., Peiris, J.S.M., Lam, S.Y., Poon, L.L.M., Yuen, K.Y., Seto, W.H. (2011). The effects of temperature and relative humidity on the viability of the SARS coronavirus. Adv. Virol. 2011, 734690. https://doi.org/10.1155/2011/734690

Chen, Z., Hao, X., Zhang, X., Chen, F. (2021). Have traffic restrictions improved air quality? A shock from COVID-19. J. Cleaner Prod. 279, 123622. https://doi.org/10.1016/j.jclepro.2020.123622

Coccia, M. (2020a). Factors determining the diffusion of COVID-19 and suggested strategy to prevent future accelerated viral infectivity similar to COVID. Sci. Total Environ. 729, 138474. https://doi.org/10.1016/j.scitotenv.2020.138474

Coccia, M. (2020b). The effects of atmospheric stability with low wind speed and of air pollution on the accelerated transmission dynamics of COVID-19, Int. J. Environ. Stud. 78, 1-27. https://doi.org/10.1080/00207233.2020.1802937

Coker, E.S., Cavalli, L., Fabrizi, E., Guastella, G., Lippo, E., Parisi, M.L., Pontarollo, N., Rizzati, M., Varacca, A., Vergalli, S. (2020). The Effects of air pollution on COVID-19 related mortality in northern Italy. Environ. Resour. Econ. 76, 611-634. https://doi.org/10.1007/s10640-020-00486-1

Conticini, E., Frediani, B., Caro, D. (2020). Can atmospheric pollution be considered a co-factor in extremely high level of SARS-CoV-2 lethality in Northern Italy? Environ. Pollut. 261, 114465. https://doi.org/10.1016/j.envpol.2020.114465

Contini, D., Costabile, F. (2020). Does air pollution influence COVID-19 outbreaks? Atmosphere 11, 377. https://doi.org/10.3390/atmos11040377

COVID-19 Dashboard India (2020). COVID-19 statistics for India. https://www.mygov.in/covid19/ (accessed 20 June 2020).

Cowling, K., Dandona, R., Dandona, L. (2014). Social determinants of health in India: Progress and in equities across States. Int. J. Equity Health 13, 1-12. https://doi.org/10.1186/s12939-0140088-0

CPCB (2014). National Air Quality Index. Control of urban pollution series CUPS 82/2014-15 (accessed 10 August 2020).

Datta, A., Saud, T., Goel, A., Tiwari, S., Sharma, S.K., Saxena, M., Mandal, T.K. (2010). Variation of ambient $\mathrm{SO}_{2}$ over Delhi. J. Atmos. Chem. 65, 127-143. https://doi.org/10.1007/s10874-0119185-2

Davis, R.E., Dougherty, E., McArthur, C., Huang, Q.S., Baker, M.G. (2016). Cold, dry air is associated with influenza and pneumonia mortality in Auckland, New Zealand. Influenza Other Respir. Viruses 10, 310-313. https://doi.org/10.1111/irv.12369

Dhaka, S.K., Chetna Kumar, V., Panwar, V., Dimri, A.P., Singh, N., Patra, P.K., Matsumi, Y., Takigawa, M., Nakayama, T., Yamaji, K., Kajino, M., Misra, P., Hayashida, S. (2020). PM2.5 diminution and haze events over Delhi during the COVID-19 lockdown period: An interplay between the baseline pollution and meteorology. Sci. Rep. 10, 13442 https://doi.org/10.1038/s41598-02070179-8

Dutta, A., Jinsart, W. (2020). Application and comparison of MLR, ANN and CART models for predicting $\mathrm{PM}_{10}$ concentration level of Guwahati city (India). Preprints 2020, 2020100146. https://doi.org/10.20944/preprints202010.0146.v1

Falagas, M.E., Theocharis, G., Spanos, A., Vlara, L.A., Issaris, E.A., Panos, G., Peppas, G. (2008). Effect of meteorological variables on the incidence of respiratory tract infections. Respir. Med. 102, 733-737. https://doi.org/10.1016/j.rmed.2007.12.010

Fareed, Z., Iqbal, N., Shahzad, F., Shah, S., Zulfiqar, B., Shahzad, K., Hashmi, S.H., Shahzad, U. (2020). Co-variance nexus between COVID-19 mortality, humidity, and air quality index in Wuhan, China: New insights from partial and multiple wavelet coherence. Air Qual. Atmos. Health 13, 673-682. https://doi.org/10.1007/s11869-020-00847-1

Gargava, P., Rajagopalan, V. (2015). Source prioritization for urban particulate emission control in India based on an inventory of $\mathrm{PM}_{10}$ and its carbonaceous fraction in six cities. Environ. Dev. 16, 44-53. https://doi.org/10.1016/j.envdev.2015.07.009

Gautam, A.S., Dilwaliya, N.K., Srivastava, A., Kumar. S., Bauddh, K., Siingh, D., Shah, M.A., Singh, K., Gautam, S. (2020). Temporary reduction in air pollution due to anthropogenic activity switch-off during COVID-19 lockdown in northern parts of India. Environ. Dev. Sustain. https://doi.org/10.1007/s10668-020-00994-6 
Gautam, S. (2020). The influence of COVID-19 on air quality in India: A boon or inutile. Bull. Environ. Contam. Toxicol. 104, 724-726. https://doi.org/10.1007/s00128-020-02877-y

Goyal, P., Sidhartha (2002). Effects of winds on $\mathrm{SO}_{2}$ and SPM concentrations in Delhi. Atmos. Environ. 36, 2925-2930. https://doi.org/10.1016/S1352-2310(02)00218-2

Guo, H., Sahu, S.K., Kota, S.H., Zhang, H. (2019). Characterization and health risks of criteria air pollutants in Delhi, 2017. Chemosphere 225, 27-34. https://doi.org/10.1016/j.chemosphere.2 019.02.154

Han, S., Bian, H., Feng, Y., Liu, A., Li, X., Zeng, F., Zhang, X. (2011). Analysis of the relationship between $\mathrm{O}_{3}, \mathrm{NO}$ and $\mathrm{NO}_{2}$ in Tianjin, China. Aerosol Air Qual. Res. 11, 128-139. https://doi.org/ 10.4209/aaqr.2010.07.0055

He, G., Pan, Y., Tanaka, T. (2020). The short-term impacts of COVID-19 lockdown on urban air pollution in China. Nat. Sustainability 3, 1005-1011 https://doi.org/10.1038/s41893-0200581-y

Health \& Family welfare, Delhi, (2020). Bulletin COVID 19. http://health.delhigovt.nic.in/ wps/wcm/connect/doit_health/Health/Home/Covid19/Bulletin+March+2020 (accessed on 20 June, 2020).

Italian Aerosol Society (2020). Information on the relationship between air pollution and the spread of COVID-19. http://www.iasaerosol.it/attachments/article/96/Nota_Informativa_IAS _English.pdf (accessed on 8 October 2020).

Jain, S., Sharma, T. (2020). Social and travel lockdown impact considering coronavirus disease (COVID-19) on air quality in megacities of India: Present benefits, future challenges and way forward. Aerosol Air Qual. Res. 20, 1222-1236. https://doi.org/10.4209/aaqr.2020.04.0171

Karuppasamy, M.B., Seshachalam, S., Natesan, U., Ayyamperumal, R., Karuppannan, S., Gopalakrishnan, G., Nazir, N. (2020). Air pollution improvement and mortality rate during COVID-19 pandemic in India: Global intersectional study. Air Qual. Atmos. Health 13, 13751384. https://doi.org/10.1007/s11869-020-00892-w

Kotnala, G., Mandal, T.K., Sharma, S.K., Kotnala, R.K. (2020). Emergence of blue sky over Delhi due to coronavirus disease (COVID-19) lockdown implications. Aerosol Sci. Eng. 4, 228-238. https://doi.org/10.1007/s41810-020-00062-6

Krishnakumar, B., Rana, S. (2020). COVID 19 in INDIA: Strategies to combat from combination threat of life and livelihood. J. Microbiol. Immunol. 53, 389-391. https://doi.org/10.1016/j.jmii. 2020.03.024

Kumar, G., Kumar, R.R. (2020). A correlation study between meteorological parameters and COVID-19 pandemic in Mumbai, India. Diabetes Metab. Syndr. 14, 1735-1742. https://doi.org/ 10.1016/j.dsx.2020.09.002

Kumar, P., Hama, S., Omidvarborna, H., Sharma, A., Sahani, J., Abhijith, K.V., Debele, S.E., ZavalaReyes, J.C., Barwise, Y., Tiwari, A. (2020). Temporary reduction in fine particulate matter due to 'anthropogenic emissions switch-off' during COVID-19 lockdown in Indian cities. Sustainable Cities Soc. 62, 102382. https://doi.org/10.1016/j.scs.2020.102382

Kumar, S. (2020). Effect of meteorological parameters on spread of COVID-19 in India and air quality during lockdown. Sci Total Environ. 745, 141021. https://doi.org/10.1016/j.scitotenv.2 020.141021

Kumari, P., Toshniwal, D. (2020). Impact of lockdown measures during COVID-19 on air qualityA case study of India. Int. J. Environ. Health Res. https://doi.org/10.1080/09603123.2020.177 8646

Kumari, S. Lakhani, A., Kumari, K.M. (2020). COVID-19 and air pollution in Indian Cities: World's most polluted cities. Aerosol Air Qual. Res. 20, 2592-2603. https://doi.org/10.4209/aaqr.2020. 05.0262

Li, J., Tartarini, F. (2020). Changes in Air quality during the COVID-19 lockdown in Singapore and associations with human mobility trends. Aerosol Air Qual. Res. 20, 1748-1758. https://doi.org/10.4209/aaqr.2020.06.0303

Lokhandwala, S., Gautam, P. (2020). Indirect impact of COVID-19 on environment: A brief study in Indian context. Environ. Res. 188, 109807. https://doi.org/10.1016/j.envres.2020.109807

Lolli, S., Chen, Y.C., Wang, S.H., Vivone, G. (2020). Impact of meteorology and air pollution on COVID-19 pandemic transmission in Lombardy region, Northern Italy. Res. Sq. https://doi.org/10.21203/rs.3.rs-39280/v1 
Ma, Y., Zhao, Y., Liu, J., He, X., Wang, B., Fu, S., Yan, J., Niu, J., Zhou, J., Luo, B. (2020). Effects of temperature variation and humidity on the death of COVID-19 in Wuhan, China. Sci. Total Environ. 724, 138226. https://doi.org/10.1016/j.scitotenv.2020.138226

Magazzino, C., Mele, M., Schneider, N. (2020). The relationship between air pollution and COVID19-related deaths: An application to three French cities. Appl. Energy 279, 115835. https://doi.org/10.1016/j.apenergy.2020.115835

Mahato, S., Pal, S., Ghosh, K.G. (2020). Effect of lockdown amid COVID-19 pandemic on air quality of the megacity Delhi, India. Sci. Total Environ. 730, 139086. https://doi.org/10.1016/j.scitoten v.2020.139086

Makinen, T.M., Juvonen, R., Jokelainen, J., Harju, T.H., Peitso, A., Bloigu, A., SilvennoinenKassinen, S., Leinonen, M., Hassi, J. (2009). Cold temperature and low humidity are associated with increased occurrence of respiratory tract infections. Respir. Med. 103, 456-462. https://doi.org/10.1016/j.rmed.2008.09.011

Mitra, A., Chaudhuri, T.R., Mitra, A., Pramanick, P., Zaman, S. (2020). Impact of COVID-19 related shutdown on atmospheric carbon dioxide level in the city of Kolkata. Parana J. Sci. Educ. 6, 8492.

Mor, S., Kumar, S., Singh, T., Dogra, S., Pandey, V., Ravindra, K. (2020). Impact of COVID-19 lockdown on air quality in Chandigarh, India: Understanding the emission sources during controlled anthropogenic activities. Chemosphere 263, 127978. https://doi.org/10.1016/j.che mosphere.2020.127978

Moriyama, M., Hugentobler, W.J., Iwasaki, A. (2020). Seasonality of respiratory viral infections. Annu. Rev. Virol. 7, 2.1-2.19. https://doi.org/10.1146/annurev-virology-012420-022445

Naeger, A.R., Murphy, K. (2020). Impact of COVID-19 containment measures on air pollution in California. Aerosol Air Qual. Res. 20, 2025-2034. https://doi.org/10.4209/aaqr.2020.05.0227

Navinya, C., Patidar, G., Phuleria, H.C. (2020). Examining effects of the COVID-19 national lockdown on ambient air quality across urban India. Aerosol Air Qual. Res. 20, 1759-1771. https://doi.org/10.4209/aaqr.2020.05.0256

Nigam, S., Rao, B.P.S., Kumar, N., Mhaisalkar, V.A. (2015). Air quality index - A comparative study for assessing the status of air quality. Res. J. Eng. Tech. 6, 1-8. https://doi.org/10.5958/2321581X.2015.00041.0

Ogen, Y. (2020). Assessing nitrogen dioxide $\left(\mathrm{NO}_{2}\right)$ levels as a contributing factor to corona-virus (COVID-19) fatality. Sci. Total Environ. 726, 138605. https://doi.org/10.1016/j.scitotenv.2020. 138605

Pansini, R., Fornacca, D. (2020). COVID-19 higher induced mortality in Chinese regions with lower air quality. medRxiv 20053595. https://doi.org/10.1101/2020.04.04.20053595

Park, H., Jeong, S., Koo, J.H., Sim, S., Bae, Y., Kim, Y., Park, C., Bang, J. (2020). Lessons from COVID19 and Seoul: Effects of reduced human activity from social distancing on urban $\mathrm{CO}_{2}$ concentration and air quality. Aerosol Air Qual. Res. 21, 200376. https://doi.org/10.4209/aaq r.2020.07.0376

Ranjan, A.K., Patra, A.K., Gorai, A.K. (2020). Effect of lockdown due to SARS COVID-19 on aerosol optical depth (AOD) over urban and mining regions in India. Sci. Total Environ. 745, 141024. https://doi.org/10.1016/j.scitotenv.2020.141024

Resmi, C.T., Nishanth, T., Satheesh Kumar, M.K., Manoj, M.G., Balachandramohan, M., Valsaraj, K.T. (2020). Air quality improvement during triple-lockdown in the coastal city of Kannur, Kerala to combat Covid-19 transmission. PeerJ. 8, e9642. https://doi.org/10.7717/peerj.9642

Rodríguez-Urrego, D., Rodríguez-Urrego, L. (2020). Air quality during the COVID-19: PM2.5 analysis in the 50 most polluted capital cities in the world. Environ. Pollut. 266, 115042. https://doi.org/ 10.1016/j.envpol.2020.115042

Sajadi, M.M., Habibzadeh, P., Vintzileos, A., Shokouhi, S., Miralles-Wilhelm, F., Amoroso, A. (2020). Temperature and latitude analysis to predict potential spread and seasonality for COVID-19. SSRN 3550308. https://doi.org/10.2139/ssrn.3550308

Sarkar, M., Das, A., Mukhopadhyay, S. (2020). Assessing the immediate impact of COVID-19 lockdown on the air quality of Kolkata and Howrah, West Bengal, India. Environ. Dev. Sustainability https://doi.org/10.1007/s10668-020-00985-7

Selvam, S., Muthukumar, P., Venkatramanan, S., Roy, P.D., Manikanda Bharath, K., Jesuraja, K. (2020). SARS-CoV-2 pandemic lockdown: Effects on air quality in the industrialized Gujarat state 
of India. Sci. Total Environ. 737, 140391. https://doi.org/10.1016/j.scitotenv.2020.140391

Sharma, M., Jain, S., Lamba, B.Y. (2020). Epigrammatic study on the effect of lockdown amid Covid-19 pandemic on air quality of most polluted cities of Rajasthan (India). Air Qual. Atmos. Health 13, 1157-1165. https://doi.org/10.1007/s11869-020-00879-7

Sharma, S., Zhang, M., Anshika, Gao, J., Zhang, H., Kota, S.H. (2020). Effect of restricted emissions during COVID-19 on air quality in India. Sci. Total Environ. 728, 138878. https://doi.org/10.101 6/j.scitotenv.2020.138878

Sharma, S.K., Mandal, T.K. (2017). Chemical composition of fine mode particulate matter (PM2.5) in an urban area of Delhi, India and its source apportionment. Urban Clim. 21, 106-122. https://doi.org/10.1016/j.uclim.2017.05.009

Shehzad, K., Sarfraz, M., Shah, S.G.M. (2020). The impact of COVID-19 as a necessary evil on air pollution in India during the lockdown. Environ. Pollut. 266, 115080. https://doi.org/10.1016/j. envpol.2020.115080

Siddiqui, A., Halder, S., Chauhan, P., Kumar, P. (2020). COVID-19 pandemic and city-level nitrogen dioxide $\left(\mathrm{NO}_{2}\right)$ reduction for urban centres of India. J. Indian Soc. Remote Sens. 48, 999-1006. https://doi.org/10.1007/s12524-020-01130-7

Singh, D.P., Gadi, R., Mandal, T.K. (2011). Characterization of particulate-bound polycyclic aromatic hydrocarbons and trace metals composition of urban air in Delhi, India. Atmos. Environ. 45, 7653-7663. https://doi.org/10.1016/j.atmosenv.2011.02.058

Singh, R.P., Chauhan, A. (2020). Impact of lockdown on air quality in India during COVID-19 pandemic. Air Qual. Atmos. Health 13, 921-928. https://doi.org/10.1007/s11869-020-00863-1

Singh, V., Singh, S., Biswal, A., Kesarkar, A.P., Mor, S., Ravindra, K. (2020). Diurnal and temporal changes in air pollution during COVID-19 strict lockdown over different regions of India. Environ. Pollut. 266, 115368. https://doi.org/10.1016/j.envpol.2020.115368

Somani, M., Srivastava, A.N., Gummadivalli, S.K., Sharma, A. (2020). Indirect implications of COVID-19 towards sustainable environment: An investigation in Indian context. Biores. Technol. Rep. 11, 100491. https://doi.org/10.1016/j.biteb.2020.100491

Srivastava, S., Kumar, A., Bauddh, K., Gautam, A.S., Kumar, S. (2020). 21-day lockdown in India dramatically reduced air pollution indices in Lucknow and New Delhi, India. Bull. Environ. Contam. Toxicol. 105, 9-17. https://doi.org/10.1007/s00128-020-02895-w

Tyagi, S., Tiwari, S., Mishra, A., Hopke, P.K., Attri, S.D., Srivastava, A.K., Bisht, D.S. (2016). Spatial variability of concentrations of gaseous pollutants across the National Capital Region of Delhi, India. Atmos. Pollut. Res. 7, 808e816. https://doi.org/10.1016/j.apr.2016.04.008

Zhang, Z., Xue, T., Jin, X. (2020). Effects of meteorological conditions and air pollution on COVID19 transmission: Evidence from 219 Chinese cities. Sci. Total Environ. 741, 140244. https://doi.org/10.1016/j.scitotenv.2020.140244

Zhu, Y., Xie, J., Huang, F., Cao, L. (2020). Association between short-term exposure to air pollution and COVID-19 infection: Evidence from China. Sci. Total Environ. 727, 138704. https://doi.org/10.1016/j.scitotenv.2020.138704

Zoran, M.A., Savastru, R.S., Savastru, D.M., Tautan, M.N. (2020). Assessing the relationship between ground levels of ozone $\left(\mathrm{O}_{3}\right)$ and nitrogen dioxide $\left(\mathrm{NO}_{2}\right)$ with coronavirus (COVID19) in Milan, Italy. Sci. Total Environ. 740, 140005. https://doi.org/10.1016/j.scitotenv.2020.140005 